\title{
Evaluation of Safety Climate, Health Concerns, and Pharmaceutical Dust Exposures at a Mail Order Pharmacy
}

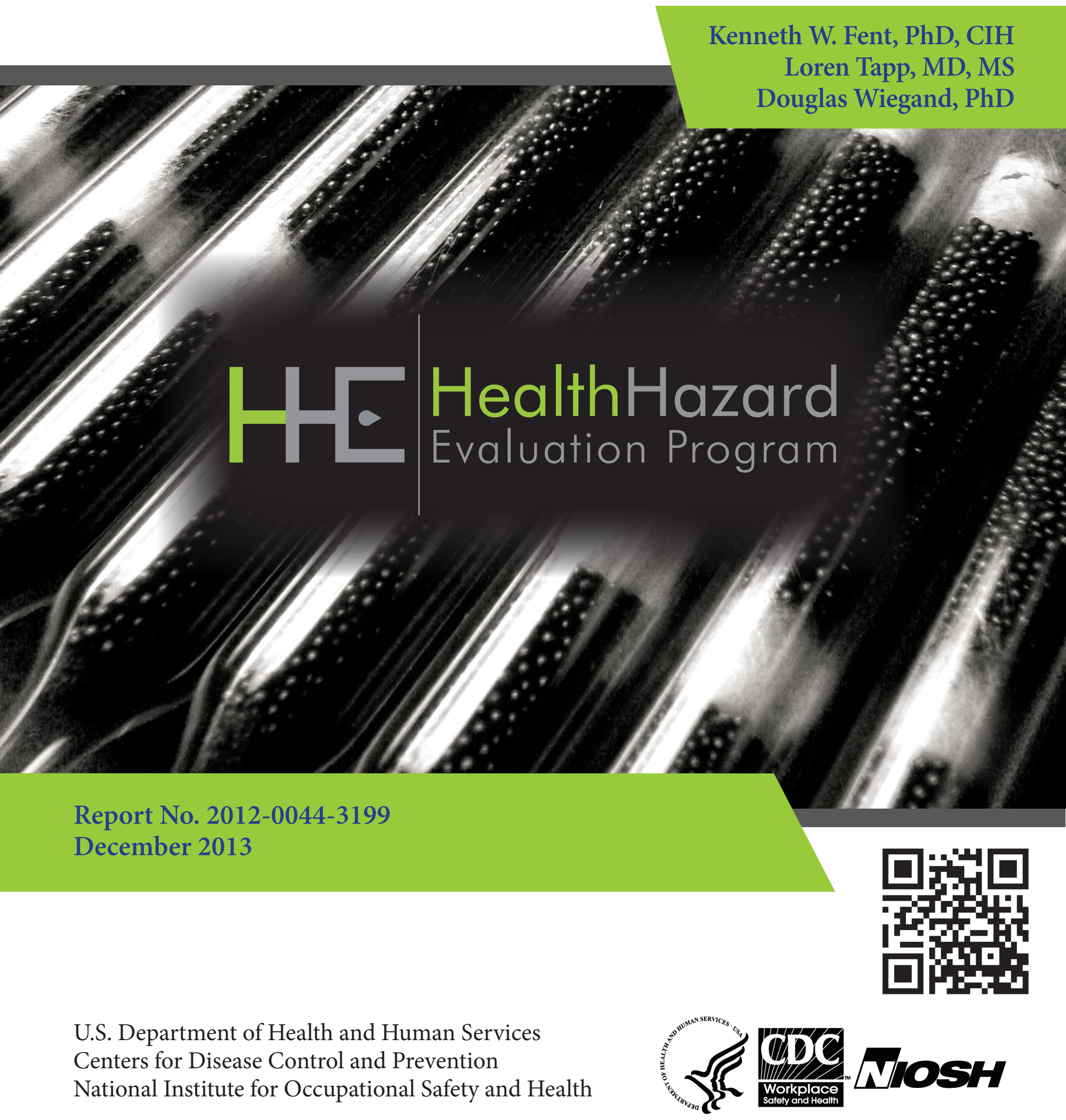




\section{Contents}

Highlights.................................................................

Abbreviations .............................................. iv

Introduction ..................................................... 1

Methods ..................................................... 3

Results ....................................................... 6

Discussion .................................................. 23

Conclusions ................................................ 28

Recommendations................................... 29

Appendix A ................................................ 33

Appendix B.................................................... 39

Appendix C................................................. 46

Appendix D .................................................. 47

References...................................................... 50

The employer is required to post a copy of this report for 30 days at or near the workplace(s) of affected employees. The employer must take steps to ensure that the posted report is not altered, defaced, or covered by other material.

The cover photo is a close-up image of sorbent tubes, which are used by the HHE Program to measure airborne exposures. This photo is an artistic representation that may not be related to this Health Hazard Evaluation. Photo by NIOSH. 


\section{Highlights of this Evaluation}

The Health Hazard Evaluation Program received a request from a mail order pharmacy.

Employees were concerned about possible health effects from exposures to hazardous drugs and pharmaceutical dust. The employees were also concerned about communication and other workplace safety climate issues.

\section{What We Did}

- We visited the pharmacy in August 2012.

- We asked employees about job stress, work-related health concerns, and perceptions of the job and social factors at work.

- We talked to employees privately about their dust exposures, health history, and possible work-related health problems.

- We measured particle levels in the air over time at different processes.

- We sampled air for dust, lactose, and active pharmaceutical ingredients. We sampled work surfaces for lactose and active pharmaceutical ingredients. Lactose is an inactive ingredient in pharmaceuticals.

\section{What We Found}

- Many contractor employees were not comfortable taking time off work when ill.

- Some employees were concerned about repetitive tasks and prolonged standing.

- Contractor employees reported more eye, nose, throat, and skin irritation and cough associated with work than company employees.

The safety climate at the pharmacy needs improvement. Employees were concerned about prolonged standing and repetitive tasks. Contractor employees reported more eye, nose, throat, and skin irritation and cough associated with work than did company employees. Employees were exposed to pharmaceutical dust. We recommend filling hazardous drug prescriptions and doing other dust-generating tasks under a local exhaust hood.

- No employees reported any changes in their health consistent with exposures to hazardous drugs.

- Employees released particles into the air during certain job tasks.

- Employees who worked in the Baker machine area had among the highest exposures to inhalable dust and lactose.

- An employee who cleaned and repaired Baker machine cells was exposed to airborne lisinopril above the exposure limit. A few employees were exposed to multiple active pharmaceutical ingredients.

- We found a hazardous drug, methotrexate, in air at levels below the manufacturer's exposure limit. We also found it on a work surface. 


\section{What We Found (continued)}

- Employees were provided vinyl gloves but no other protective clothing. We measured lactose on work surfaces and saw pharmaceutical dust on personal clothing. Take-home exposure is possible.

\section{What the Employer Can Do}

- Create a health and safety committee.

- Create a list of pharmaceuticals that are dusty, along with any exposure guidelines. Use this information to determine how to handle these pharmaceuticals.

- Use local exhaust ventilation hoods that are ducted outdoors for filling hazardous drug prescriptions and other tasks that could create pharmaceutical dust.

- Provide seats at workstations.

- Stop the punitive "point system" for discouraging absences.

- Require employees to wear nitrile gloves. Provide safety glasses and long-sleeve protective clothing to employees who hand fill hazardous drug prescriptions or create pharmaceutical dust.

\section{What the Employees Can Do}

- Tell your supervisor or occupational safety and health specialist if you have workplace concerns or suggestions for improving the health and safety at the workplace.

- Follow the procedures for using and maintaining the local exhaust hood.

- Wear all required personal protective equipment and clothing. 
This page left intentionally blank. 


\section{Abbreviations}

$\begin{array}{ll}\mu \mathrm{m} & \text { Micrometer } \\ \mu \mathrm{g} / \mathrm{m}^{3} & \text { Micrograms per cubic meter } \\ \text { API } & \text { Active pharmaceutical ingredient } \\ \text { BVNA } & \text { Bureau Veritas North America } \\ \text { HCTZ } & \text { Hydrochlorothiazide } \\ \text { HEPA } & \text { High efficiency particulate air } \\ \mathrm{M} & \text { Mean/average } \\ \mathrm{MDC} & \text { Minimum detectable concentration } \\ \mathrm{mL} & \text { Milliliter } \\ \mathrm{mL} / \mathrm{min} & \text { Milliliter per minute } \\ \mathrm{mm} & \text { Millimeter } \\ \mathrm{mM} & \text { Millimolar } \\ \mathrm{MQC} & \text { Minimum quantifiable concentration } \\ \mathrm{n} & \text { Number of samples } \\ \mathrm{N} & \text { Number of employees } \\ \mathrm{NA} & \text { Not applicable } \\ \mathrm{ND} & \text { Not detectable } \\ \mathrm{NIOSH} & \text { National Institute for Occupational Safety and Health } \\ \text { OEL } & \text { Occupational exposure limit } \\ \text { OSHA } & \text { Occupational Safety and Health Administration } \\ \text { Particles/L } & \text { Particles per liter } \\ \end{array}$




\section{Introduction}

The Health Hazard Evaluation Program received a request from a mail order pharmacy. The pharmacy's contractor employees who submitted the request were concerned about exposures to pharmaceutical dust, including hazardous drugs, and the potential health effects from those exposures. They also were concerned about communication and other workplace health and safety climate issues. We evaluated pharmaceutical exposures, health effects, job stress, workrelated health concerns, and psychosocial factors at the pharmacy in August 2012. In March 2013, we sent an interim report summarizing the type and number of samples collected.

The mail order pharmacy filled prescriptions using automated and manual distribution systems for delivery to its customers throughout the country. Approximately 175 employees worked on either the first or second shift. The majority were non-unionized contractors who reported to their own managers. The remaining employees were unionized company employees. On average, the company filled 74,000 prescriptions per day during our evaluation. All prescriptions were verified by pharmacists. Most of these were unit-of-issue prescriptions that do not require counting. These were processed in the A-frame area of the pharmacy.

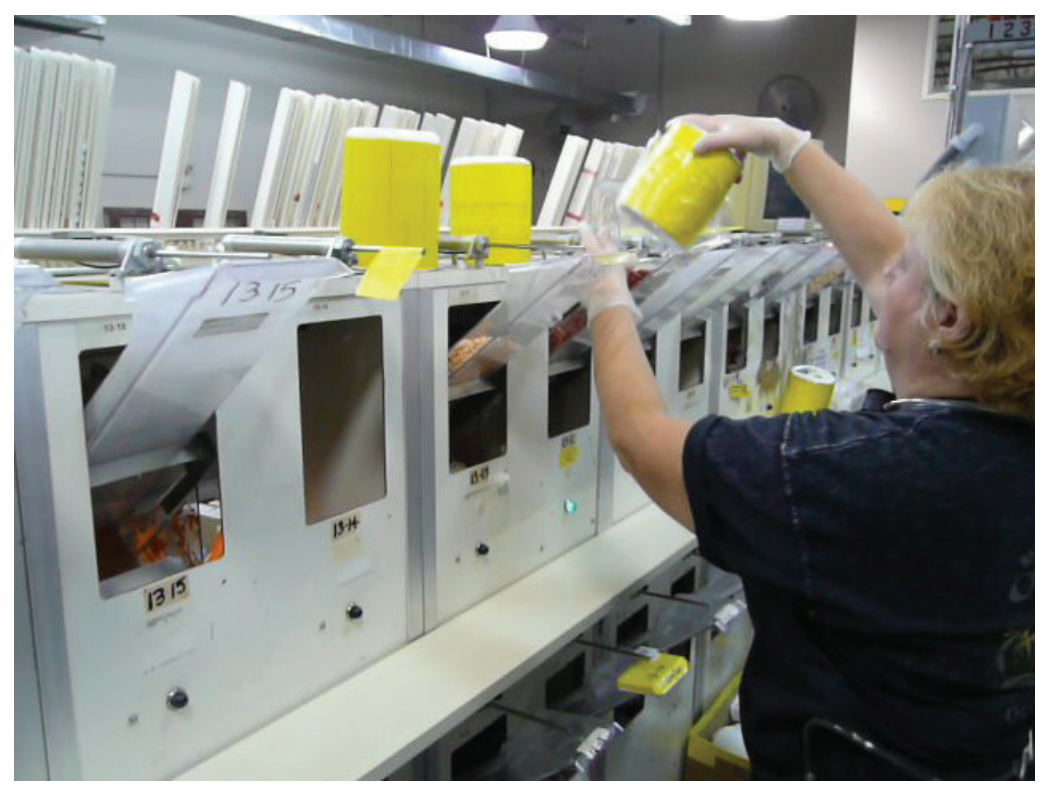

Figure 1. Pharmacy technician filling canisters on the platform above the Baker machine. Photo by NIOSH.
A Baker automatic dispensing machine (McKesson Corporation) was used for many of the commonly prescribed pharmaceuticals. This machine had an elevated work platform where canisters containing pharmaceuticals were located. Pharmacy technicians periodically refilled these canisters by emptying original manufacturer bottles containing the appropriate pharmaceuticals into cups that were then emptied into the labeled canisters (Figure 1). The pharmaceuticals in the canisters were gravity

fed into the cells below the platform. A conveyor belt on the outside of the machine carried empty prescription bottles to a nozzle below the appropriate cell, and a valve in the cell opened to dispense the pharmaceutical into the bottle (Figure 2). Pharmacy technicians maintained the Baker machine. This included freeing jams, identifying bottles that did not receive pharmaceuticals, and cleaning and repairing malfunctioning cells. To clean or repair the cells, the pharmacy technicians emptied the cell into a bin, vacuumed the inside of the cell using a $3 \mathrm{M}$ vacuum with highefficiency particulate air (HEPA) filtration, wiped the inside of the cells with isopropyl alcohol, made any necessary repairs, and returned the pharmaceuticals to the cells. According to the 


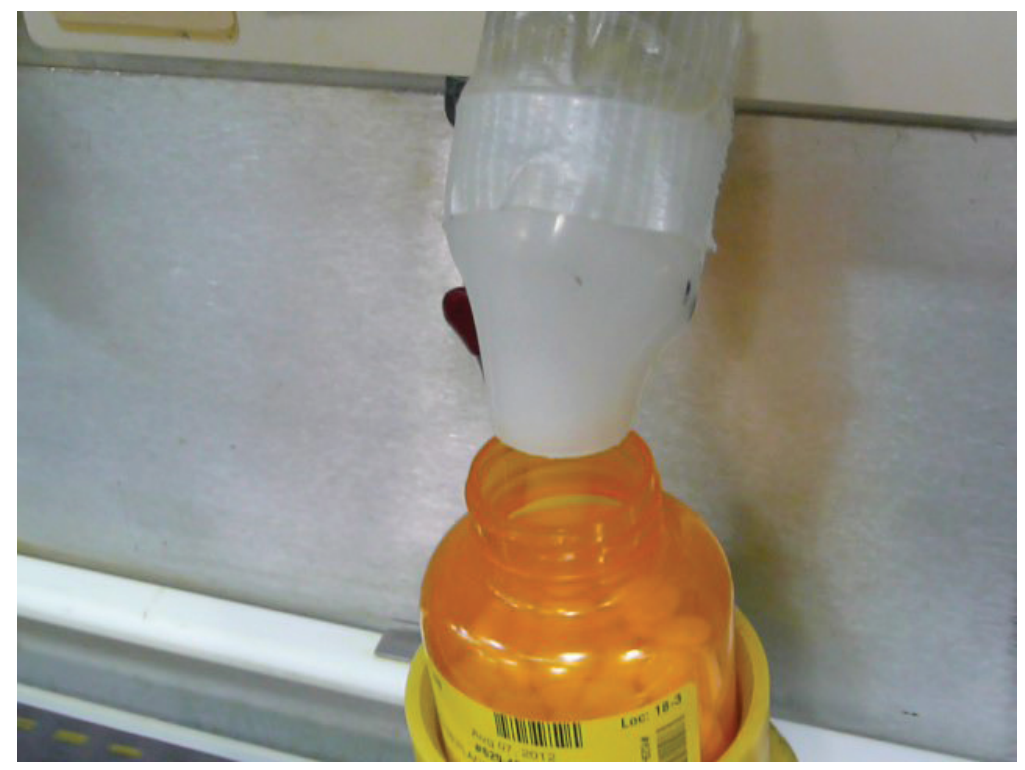

Figure 2. Baker machine nozzle where pharmaceuticals were dispensed into prescription bottles. Photo by NIOSH. standard operating procedures, the pharmacy technicians were required to do this work inside a recirculating exhaust hood with HEPA filtration (Labconco XPert Filtered Balance System). The pharmacy had standard operating procedures for determining when to change the HEPA filter (using pressure drop) and how to change the HEPA filter (bag-in/bag-out) in the exhaust hood. These procedures were based on the manufacturer's guidelines.

Pharmacy technicians also filled prescriptions in the manual count, controlled drug (controls), and bulk/hazardous drug areas of the pharmacy. They used KirbyLester desktop automated counters to fill less common or special-handling prescriptions in the manual count area. They hand filled prescriptions for controlled substances (Schedule III-V), mostly with unit of issue pre-counted bottles, in the controls area. In addition, they prepared bulk prescriptions (e.g., insulin) and occasionally hand filled hazardous drug prescriptions in the bulk/hazardous drug area. Hazardous drugs are drugs known or suspected to cause adverse health effects from exposures in the workplace [NIOSH 2004]. The pharmacy stocked 54 hazardous drugs included on the National Institute for Occupational Safety and Health (NIOSH) list of hazardous drugs [NIOSH 2012], 32 of which were available as tablets. Tablets are more likely than capsules to produce airborne dust.

The pharmacy had standard operating procedures for the safe handling of pharmaceuticals, including hazardous drugs. All hazardous drugs (as defined by the NIOSH list [NIOSH 2012]) were stored in a cabinet labeled "cytotoxics." Employees were required to wear vinyl gloves when filling these prescriptions. They were also required to clean their workstations and counting trays with isopropyl alcohol wipes immediately after filling these prescriptions. Employees who unpacked boxes containing hazardous drug shipments were not required to wear gloves. In case of a hazardous drug spill, employees were required to notify personnel in the area and a supervisor. Employees trained on hazardous spill clean-up procedures were responsible for cleaning the spills. Spill kits were available and included cleaning supplies and neoprene gloves.

Employees performed other jobs including labeling, packaging, housekeeping, and administrative functions. Administrative functions were performed in offices that were separated from the rest of the pharmacy. Employees put labels on prescription bottles in the labeling area. Employees put filled prescriptions into mailing envelopes or boxes in the packaging area. The packaging area was located next to the Baker machine area. The housekeeping employees swept the floors with a 
broom and disposed of trash. They also used a Dayton® Model 3UP66 12-gallon wet/dry vacuum to clean the surfaces of the Baker machine during break periods. This vacuum contained a HEPA filter, and the vacuum bags used were rated high efficiency for fine dust collection.

All employees were required to wear vinyl gloves (High Five 600 Series) when handling pharmaceuticals. No other personal protective equipment or clothing was required. However, NIOSH-approved filtering facepiece respirators (Honeywell/Wilson Saf-T-Fit Plus) and hearing protection (3M Tekk/AO Safety Product no. 90581) were available for voluntary use. All employees were provided with Appendix D of the Occupational Safety and Health Administration (OSHA) respiratory protection standard [29 CFR 1910.134].

In general, company employees performed most administrative functions, and contractor employees performed most production functions (e.g., filling, labeling, packaging, and housekeeping). Company and contractor pharmacists and pharmacy technicians often worked side-by-side. Company employee safety and health issues were reported to company management; contractor employee safety and health issues were reported to contractor management and the company safety committee that included contractor and company management representatives.

\section{Methods}

We evaluated the pharmacy for 3 days in August 2012. Our objectives were to (1) assess safety climate, job stress, work-related health concerns, and psychosocial factors among employees; (2) evaluate potential work-related employee symptoms and health problems; (3) determine if and how pharmaceutical dust was released into the air; (4) measure the concentration of the airborne dust; (5) measure specific active pharmaceutical agents (APIs) and other pharmaceutical ingredients in the airborne dust; and (6) determine if surfaces were contaminated with pharmaceutical ingredients.

\section{Employee Surveys}

We asked 71 full-time, non-supervisory employees who worked with pharmaceuticals on two shifts to complete a survey about safety climate, psychosocial factors in the workplace, job stress, work-related health concerns, and employer-employee relations. We selected 50 of the 157 contractor employees from roster lists using a systematic pattern, choosing every third, then every fourth employee, and repeating this pattern down the list. Because so few company employees worked with pharmaceuticals, we asked all 18 of them to participate. We selected 3 of 7 housekeeping employees based on their availability. One additional contractor employee voluntarily participated in the survey but not in the medical interview $(\mathrm{N}=72)$.

The first section of the survey instructed employees to rate their level of agreement with 14 statements exploring safety climate. Responses to these survey questions were measured with a five-point scale ranging from 1 ("strongly disagree") to 5 ("strongly agree"). Safety climate refers to employees' perceptions of the safety-related aspects of how their organization operates. One method of measuring safety climate [Neal et al. 2000] focuses on individual perceptions of how 
the organization values safety, comprised of the following dimensions: management values (the extent to which the employer places a high priority on safety), safety communication (the extent to which an open exchange of information regarding safety exists), safety training (the extent to which training is accessible, relevant, and comprehensive), and safety systems (the extent to which safety policies and procedures are perceived to be effective in preventing safety incidents) [Neal et al. 2000]. We also included the dimension of safety risk (the extent to which employees believe they are exposed to inherent dangers of the workplace). Internal consistency for the items measuring these five dimensions was analyzed using Cronbach's coefficient $(\alpha)$ after adjusting for the directionality of items, where necessary. We created composite scores for survey items within the management values, safety communication, safety training, safety systems, and safety risk dimensions where $\alpha>0.7$ by calculating the mean of the individual scores for each respondent.

The second section of the survey included questions targeting specific psychosocial factors of interest to the HHE requestors, including perceptions of job security, attending work while ill, and perceived hostility from management. These items were rated with a five-point scale ranging from 1 ("strongly disagree") to 5 ("strongly agree").

The third section of the survey included questions with 11-point response scales and open-ended questions regarding job stress, work-related health concerns, and perceptions of the relationship between employees and their employer.

\section{Employee Medical Interviews}

The 71 employees who participated in the survey also met with us individually for confidential medical interviews. We asked employees about demographic information, work exposure history, medical history (including reproductive health and hormone disorders), and whether they had any work-related health problems. We asked if the employee had experienced specific symptoms such as eye, nose, throat, or skin irritation, respiratory symptoms, dizziness, and heart palpitations, in the past month and if symptom(s) were better, worse, or unchanged when away from work. If the symptom(s) experienced were better when away from work, we defined those symptoms to be "work-related." We also asked if the employees had any comments or concerns about their work.

\section{Air Sampling}

We used the air sampling methods summarized in Table 1. We selected employees for personal air sampling among the various job tasks at the pharmacy, focusing primarily on employees who did tasks or were near tasks that we thought could generate pharmaceutical dust. In 3 days, we collected 37 personal air samples, including three sets of side-by-side samples, by attaching the air samplers to the employees' shirt collars. We collected 21 area air samples at fixed locations throughout the pharmacy. These 58 air samples measured inhalable dust, which is dust that could be inhaled and deposited anywhere in the respiratory system including the nose and mouth [ACGIH 2013]. Sampling for inhalable dust is the preferred method for assessing this type of exposure, because most pharmaceuticals are water soluble and can be absorbed anywhere in the respiratory system. Of the 58 samples, 54 were full-shift samples collected during first shift. Three samples were collected for part of second shift (day 2), and one sample was collected during a specific task. 
Table 1. Summary of the air sampling methods

\begin{tabular}{|c|c|c|c|c|}
\hline Analytes & Method & $\begin{array}{c}\text { No. of } \\
\text { personal } \\
\text { samples }\end{array}$ & $\begin{array}{c}\text { No. of } \\
\text { area } \\
\text { samples }\end{array}$ & Comments \\
\hline Inhalable dust & NIOSH Method 0600* & 37 & 21 & - Total no. of inhalable \\
\hline Lactose & BVNA internal method $\dagger$ & 22 & 15 & \\
\hline HCTZ & BVNA internal method $†$ & 2 & 7 & \multirow{3}{*}{$\begin{array}{l}\text { Collected on tared, } \\
\text { 25-mm diameter } \\
\text { polytetrafluoroethylene } \\
\text { sample filters. }\end{array}$} \\
\hline Lisinopril & BVNA internal method $†$ & 2 & 7 & \\
\hline Hydrocodone & BVNA internal method $†$ & 4 & 1 & \\
\hline Warfarin & BVNA internal method $\dagger$ & 3 & 0 & \multirow{4}{*}{$\begin{array}{l}\text { - Used Institute of } \\
\text { Medicine samplers } \\
\text { operating at a flow rate } \\
\text { of } 2 \mathrm{Lpm} \text {. }\end{array}$} \\
\hline Methotrexate & BVNA internal method $†$ & 1 & 2 & \\
\hline Methocarbamol & BVNA internal method $†$ & 1 & 1 & \\
\hline Levothyroxine & BVNA internal method $\dagger$ & 1 & 1 & \\
\hline Buspirone & BVNA internal method $\dagger$ & 1 & 0 & \multirow{6}{*}{$\begin{array}{l}\text { - Subsequently analyzed } \\
\text { as noted. }\end{array}$} \\
\hline Gabapentin & BVNA internal method $†$ & 1 & 0 & \\
\hline Captopril & BVNA internal method $\dagger$ & 1 & 0 & \\
\hline Naproxen & BVNA internal method $\dagger$ & 1 & 0 & \\
\hline Furosemide & BVNA internal method $†$ & 1 & 0 & \\
\hline Triamterene & BVNA internal method $\dagger$ & 0 & 1 & \\
\hline Particle count & NA & NA & NA & $\begin{array}{l}\text { 6-channel optical } \\
\text { particle counter, } \\
\text { real-time }\end{array}$ \\
\hline
\end{tabular}

BVNA = Bureau Veritas North America

$\mathrm{HCTZ}=$ hydrochlorothiazide

$\mathrm{mm}=$ millimeter

$\mathrm{NA}=$ not applicable

${ }^{*} \mathrm{NIOSH}$ Manual of Analytical Methods [NIOSH 2013b]

†More information on the BVNA analytical methods is provided in Appendix A.

We followed some of the employees who wore air samplers throughout their workday and held real-time optical particle counters (MetOne HHPC-6) near their breathing zones to identify dusty tasks that appeared as peaks in particle number concentrations on the optical particle counters. We also noted the types of tablets handled so that we could later identify which personal air samples (previously analyzed gravimetrically) could be further analyzed for lactose (common inactive filler in tablets) and/or specific active pharmaceutical ingredients (APIs) (Table 1). Although lactose is inactive, its presence in air at levels above background (i.e., levels in nonproduction areas) suggests that pharmaceuticals were the source of some of the airborne dust. 
The side-by-side personal air samples that we collected allowed us to quantify more than one API in an employee's breathing zone. We used information on the dustiness of pharmaceuticals to identify area air samples for analysis of lactose and/or APIs. We generally focused on APIs that had occupational exposure limits (OELs) or hazard control bands established by pharmaceutical manufacturers. We also made sure that our contract lab, BVNA, had methods for the APIs we selected. More information on the analytical methods is provided in Appendix A. Methotrexate was the only API we selected for analysis from the NIOSH list of hazardous drugs [NIOSH 2012].

\section{Surface Sampling}

Table 2 summarizes the surface sampling methods used during the evaluation. We sampled 22 surfaces for pharmaceutical ingredients to estimate the extent of pharmaceutical dust contamination throughout the pharmacy. The surfaces we sampled were primarily work surfaces in offices, near the Baker machine, or in the controls area. We placed a 10 centimeters by 10 centimeters template on top of a surface. While wearing nitrile gloves, we wiped the work surface area inside the template with a prewetted AlphaWipe $\AA$ towelette (Texwipe ${ }^{\circledR}$ TX1004) in three different directions. For irregularly-shaped surfaces, we estimated 100 square centimeters and wiped the surface in a manner identical to that used for flat surfaces.

Table 2. Summary of the surface sampling methods

\begin{tabular}{|c|c|c|c|}
\hline Analytes & Method & No. of samples & Comments \\
\hline Lactose & BVNA internal method* & 9 & \multirow{3}{*}{$\begin{array}{l}\text { Total no. of wipe } \\
\text { samples }=22 \text {. }\end{array}$} \\
\hline Methotrexate & BVNA internal method* & 8 & \\
\hline Hydrocodone & BVNA internal method* & 3 & \\
\hline Methocarbamol & BVNA internal method* & 1 & \multirow{2}{*}{$\begin{array}{l}\text { - Used towelettes } \\
\text { prewetted with de- } \\
\text { ionized water. }\end{array}$} \\
\hline Glipizide & BVNA internal method* & 1 & \\
\hline
\end{tabular}

${ }^{*}$ More information on the BVNA analytical methods is provided in Appendix A.

\section{Results}

\section{Employee Surveys and Medical Interviews}

We selected 71 employees to interview, as described previously, and all consented to participate. One additional contractor employee voluntarily participated in the survey but not in the medical interview ( $\mathrm{N}=72$ ). Job titles of the employees (excluding the housekeepers) included pharmacy technicians, pharmacists, shipper/packers, material handlers, supply technicians, and industrial equipment mechanics. Table 3 shows the number of employees in each job title among company and contractor employees. 
Table 3. Job titles among participating company $(N=18)$ and contractor employees $(N=50)$

\begin{tabular}{lcc}
\hline Job title & Company employees & Contractor employees \\
& $\mathrm{N}(\%)$ & $\mathrm{N}(\%)$ \\
\hline Pharmacists & $2(11)$ & $4(8)$ \\
Pharmacy technicians & $11(61)$ & $33(66)$ \\
Shipping/packing & 0 & $13(26)$ \\
Material handler & $3(17)$ & 0 \\
Supply and equipment mechanics & $2(11)$ & 0 \\
\hline
\end{tabular}

Because the housekeeping employees were few and employed by a different contractor, we briefly summarize their responses to the surveys and interviews in the text rather than the tables or figures. Overall, the housekeeping employees' responses did not indicate problems regarding safety climate or job stress.

Table 4 compares demographic information between company and contractor employees. Company and contractor employees were similar in age, sex, and the number of years working at their current job.

Table 4. Demographic information reported by company $(N=18)$ and contractor employees $(N=50)$

\begin{tabular}{lcc}
\hline Demographic & Company employees & Contractor employees \\
\hline Number female (\%) & $12(67)$ & $38(76)$ \\
Average age in years (range) & $42(26-55)$ & $41(21-74)$ \\
Average years in this job (range) & $4(0.33-16)$ & $5(0.08-15)$ \\
\hline
\end{tabular}

\section{Employee Survey}

The first section of the survey explored employees' perceptions of safety climate. Mean scores $(\mathrm{N}=69)$ of the composite safety climate dimensions were calculated based on a fivepoint scale, with higher numbers indicating a more positive response. The most highly rated safety climate dimension was management value for safety $(\mathrm{M}=3.9)$, followed by safety training $(\mathrm{M}=3.8)$, safety systems $(\mathrm{M}=3.5)$, safety communication $(\mathrm{M}=3.5)$, and safety risk $(\mathrm{M}=3.4)$. Overall, employees reported positive perceptions of safety climate. Among pharmacists and pharmacy technicians (the most prevalent job title), however, the perceptions about safety climate were more positive among those employed by the company than those employed by the contractor (Table 5). This was especially true for the safety training and safety risk dimensions. 
Table 5. Safety climate dimension mean scores for pharmacists/pharmacy technicians by employer

\begin{tabular}{lcc}
\hline Safety climate dimension & $\begin{array}{c}\text { Company pharmacists/pharmacy } \\
\text { technicians }(\mathrm{N}=14) \\
\text { Mean }\end{array}$ & $\begin{array}{c}\text { Contractor pharmacists/pharmacy } \\
\text { technicians }(\mathrm{N}=37) \\
\text { Mean }\end{array}$ \\
\hline $\begin{array}{l}\text { Management value for } \\
\text { safety }\end{array}$ & 4.3 & 3.8 \\
Safety training & 4.4 & 3.6 \\
Safety communication & 3.9 & 3.4 \\
Safety systems & 3.8 & 3.5 \\
Safety risk & 4.3 & 3.3 \\
\hline
\end{tabular}

*Survey items reversed scored

We asked employees to rate their level of agreement with several statements regarding job security, comfort with taking a sick day if not feeling well, and perceived hostility from management. These were issues of specific interest to the HHE requestors. We analyzed these variables by employer, since company and contractor employees could have different experiences with each. Table 6 shows the proportions of contractor and company employees who indicated agreement with the statements by scoring the question as either a 4 or 5 on the five-point scale (where 5 is "strongly agree").

Table 6. Number of employees agreeing with survey items by employer (company employees $\mathrm{N}=$ 18; contractor employees $\mathrm{N}=51$ )

\begin{tabular}{lcc}
\hline Survey item & $\begin{array}{c}\text { Number of } \\
\text { company } \\
\text { employees (\%) } \\
\text { in agreement }\end{array}$ & $\begin{array}{c}\text { Number of } \\
\text { contractor } \\
\text { employees (\%) } \\
\text { in agreement }\end{array}$ \\
\hline I am satisfied with my level of job security & $16(89)$ & $21(41)$ \\
I am comfortable taking a sick day if I am not feeling well & $15(83)$ & $5(10)$ \\
I am exposed to hostility or conflict from my supervisor & $1(6)$ & $16(31)$ \\
\hline
\end{tabular}

Most company employees were satisfied with their level of job security and felt comfortable taking a sick day if they were not feeling well. Very few company employees reported facing hostility from their supervisors.

Most contractor employees reported that they were not satisfied with job security and few $(10 \%)$ reported that they were comfortable taking a sick day when ill. Approximately one third of contractor employees reported facing hostility from their supervisor.

\section{Job Stress}

We asked participants to rate their level of job stress over the past week on a scale from 0 (as low as it can be) to 10 (as high as it can be). The average job stress score for all employees was $4.3(\mathrm{~N}=69)$. When separated by employer, the average job stress score was $3.8(\mathrm{~N}=$ $18)$ for company employees and $4.5(\mathrm{~N}=51)$ for contractor employees. When grouped by job titles, shipper/packers had the highest average job stress score of $4.8(\mathrm{~N}=14)$, followed by pharmacists/pharmacy technicians $(\mathrm{M}=4.2 ; \mathrm{N}=51)$, and material handlers/suppliers/ equipment mechanics (grouped due to a small number of employees with these job titles; $\mathrm{M}$ $=4.0 ; \mathrm{N}=4)$. 


\section{Company Employees' Reported Job Stressors}

We asked participants to identify one or more major source(s) of job stress, if any, in an openended question. Twelve (66\%) company employees reported one or more job stressor(s).

Three company employees reported interpersonal problems with their supervisor as being a job stressor. Other job stressors were reported, but each of these were reported by less than three individuals and are therefore not listed here.

\section{Contractor Employees' Reported Job Stressors}

Thirty-eight (75\%) contractor employees reported one or more job stressor(s). Job stressors reported by three or more participating contractor employees are listed in Table 7.

Table 7. Frequency of reported job stressors for contractor employees $(\mathrm{N}=51)$

\begin{tabular}{lc}
\hline Job stressor & $\begin{array}{c}\text { Number (\%) of } \\
\text { contractor employees } \\
\text { reporting }\end{array}$ \\
\hline Lack of sick leave & $15(29)$ \\
No stressors reported & $13(25)$ \\
Interpersonal problems with & $11(22)$ \\
supervisor & $10(20)$ \\
High workload & $6(12)$ \\
Poor communication at work & $4(8)$ \\
Interpersonal problems with & \\
coworkers & $4(8)$ \\
Concern about making errors & $4(8)$ \\
Concern about losing one's job & \\
\hline
\end{tabular}

Contractor employees were not allowed sick leave and received "points" for absences and tardiness. Employees received 3-6 points for an absence, depending on the day of the week. Employees received 1 point for up to 15 minutes tardiness initially and then 2 points for each subsequent 15-minute period. The points were cumulative and led to disciplinary actions ranging from a verbal warning ( 9 points) to 3 months of probation ( 21 points). Each quarter, employees with perfect attendance were rewarded with a 3-point deduction. Employees reported that the point system created job stress related to fear of punishment, lack of control, and interference with work-life balance (e.g., needing to stay home to care for an ill child). Some employees also reported concerns that they were being exposed to germs from ill coworkers. The other most frequently reported job stressors included having interpersonal problems with one's supervisor and a heavy workload.

\section{Work-related Health Concerns}

We asked participants to rate their level of work-related health concern on a scale from 0 (as low as it can be) to 10 (as high as it can be). The average work-related health concern score for all employees was $4.1(\mathrm{~N}=68)$. Contractor employees had a higher average work-related 
health concern score $(M=4.8 ; N=51)$ than company employees $(M=2.1 ; N=17)$. This remained true when comparing the pharmacists/pharmacy technicians between contractor $(\mathrm{M}=4.2 ; \mathrm{N}=14)$ and company employees $(\mathrm{M}=1.3 ; \mathrm{N}=37)$. When grouped by job titles, shipper/packers had the highest average work-related health concern score of $6.4(\mathrm{~N}=$ $14)$, followed by material handlers/suppliers/equipment mechanics $(\mathrm{M}=4.5 ; \mathrm{N}=4)$ and pharmacists/pharmacy technicians $(\mathrm{M}=3.4 ; \mathrm{N}=50)$.

\section{Company Employees' Reported Work-Related Health Concerns}

We asked participants to explain their work-related health concern score in an openended question. Four (22\%) company employees responded to this item. Two company employees reported a concern about developing a musculoskeletal disorder. Several other concerns were reported, but each concern was only reported by a single individual and is therefore not listed here.

\section{Contractor Employees' Reported Work-Related Health Concerns}

Thirty-two (63\%) contractor employees responded to the open-ended question. Work-related health concerns reported by three or more contractor employees are listed in Table 8.

Table 8. Frequency of contractor employees' reported workrelated health concerns $(\mathrm{N}=51)$

\begin{tabular}{lc}
\hline Work-related health concern & $\begin{array}{c}\text { Number of contractor } \\
\text { employees reporting } \\
\mathrm{N}(\%)\end{array}$ \\
\hline $\begin{array}{l}\text { No work-related health concern(s) } \\
\text { reported }\end{array}$ & $19(37)$ \\
$\begin{array}{l}\text { Prolonged standing } \\
\text { Exposure to pill dust }\end{array}$ & $14(27)$ \\
$\begin{array}{l}\text { Repetitive motion leading to potential } \\
\text { musculoskeletal disorder }\end{array}$ & $14(27)$ \\
$\begin{array}{l}\text { Noise } \\
\text { Indoor environmental quality affecting } \\
\text { health }\end{array}$ & $10(20)$ \\
\hline
\end{tabular}

\section{Perceptions of the Relationship between Employees and Employers}

\section{Company Employees}

We asked survey participants to describe their perceptions of the relationship between employees and employers in an open-ended question. Comments made by three or more individuals are listed in Table 9. 
Table 9. Descriptions of the employer-employee relationship among company employees $(\mathrm{N}=18)$

\begin{tabular}{ll}
\hline $\begin{array}{l}\text { Description of supervisor-employee } \\
\text { relationship }\end{array}$ & $\begin{array}{c}\text { Number of } \\
\text { participants } \\
\text { reporting } \\
\mathrm{N}(\%)\end{array}$ \\
\hline The relationship is positive & $9(50)$ \\
There is open communication & $3(17)$ \\
Supervisors address employees' concerns & $3(17)$ \\
My supervisor is "distant" & $3(17)$ \\
No response & $2(11)$ \\
\hline
\end{tabular}

\section{Contractor Employees}

Comments made by at least three contractors regarding the employer-employee relationship are listed in Table 10.

Table 10. Descriptions of the employer-employee relationship among contractor employees $(\mathrm{N}=51)$

\begin{tabular}{lc} 
Description of employer-employee relationship & $\begin{array}{c}\text { Number of contractor } \\
\text { employees reporting } \\
\text { N (\%) }\end{array}$ \\
\hline There is a poor relationship & $22(43)$ \\
There is poor communication between my supervisor and employees & $14(27)$ \\
The relationship is positive & $10(20)$ \\
My supervisor is disrespectful to employees & $10(20)$ \\
My supervisor shows favoritism towards certain employees & $9(18)$ \\
My supervisor is "distant" & $8(16)$ \\
My supervisor is unapproachable & $6(12)$ \\
My supervisor is intimidating & $5(10)$ \\
My supervisor offers no praise for good work & $5(10)$ \\
Employees are treated "like machines" & $5(10)$ \\
Employees are limited in who they can voice concerns to & $3(6)$
\end{tabular}

\section{Medical Interviews}

Most contractor employees ( 32 of 50) reported handling what they considered to be hazardous drugs; however, 10 reported only handling warfarin, which is not on the NIOSH list of hazardous drugs. Of the remaining 22 employees, four said they only handled hazardous drugs if a bottle spilled. Five of the 18 company employees reported handling hazardous drugs. When we looked only at employees whose job titles were pharmacist or pharmacy technician, we found about the same percentages of company (31\%) and contractor (30\%) pharmacists/pharmacy technicians reported handling hazardous drugs. However, over twice the percentage of contractor pharmacists/pharmacy technicians (70\%) reported working on the Baker machine as company pharmacists/pharmacy technicians (31\%).

When asked about their medical history, six contractor employees (five pharmacists/ pharmacy technicians and one shipper/packer) reported having asthma or asthma-like 
symptoms; four of the six reported having asthma prior to being hired, and two reported developing asthma-like symptoms since being hired (one pharmacist/pharmacy technician and one shipper/packer). Some employees with pre-existing asthma reported having more asthma symptoms at work. No company employees reported having asthma.

When we asked about hormone problems, five company and seven contractor employees reported thyroid disorders including hypothyroidism (6), hyperthyroidism (1), noncancerous thyroid tumor (1), and unknown type (4). All of these employees were female pharmacists/ pharmacy technicians, at least eight had been diagnosed with the disorder prior to working at this facility, and more than half had worked with pharmaceuticals prior to this job. No employees reported being diagnosed with cancer, reproductive or immunodeficiency disorders, miscarriages, or giving birth to a child with a birth defect since being hired.

When asked "do you think you have any health problems related to working at [this company]?" 17 employees responded "yes," 2 company and 15 contractor employees. Of the two company employees, one reported breaking out in hives twice when working in the Baker machine area, and one reported recurrent headaches. Both employees had sought medical care. Of the 15 contractor employees reporting a possible work-related health problem, ten reported musculoskeletal problems, four reported respiratory problems, three reported headaches, and one reported an infection. The musculoskeletal illnesses included back, foot, knee, leg, shoulder, hand/wrist, arm, and neck pain, with no one type reported by more than three employees. Ten of the 15 employees had seen a medical provider. When asked what they thought caused their health problem, six reported repetitive tasks, four reported prolonged standing, three reported pill dust, two reported stress, one reported noise, and two did not know.

Most of the interviewed employees reported wearing gloves when handling hazardous drugs and when cleaning the Baker machine. Some employees reported wearing an N95 filtering facepiece respirator during certain activities, such as cleaning up spills or cleaning the Baker machine. Some shipping/packing employees were concerned that they were being exposed to dust from the adjacent Baker machine and/or pill dust on the outside of prescription bottles that they handled when preparing them for shipping.

The three housekeeping employees had worked at the facility 3 years or less. None reported a work-related health problem, although one reported eye irritation that was worse at work, and one reported throat irritation that was worse at work.

\section{Symptom Survey}

Table 11 describes the responses to a symptom survey among company and contractor employees. Employees were asked if they had any of these symptoms in the past month and whether the symptom was better, worse, or the same when off of work. If the symptom was better when off of work, we defined the symptom as being associated with work. Although several symptoms had low numbers of employees reporting them, the percentage of contractor employees reporting eye, nasal, throat, and skin irritation and cough that were associated with work was more than twice that of company employees. 
Table 11. Health symptoms in the month before our visit among company employees $(\mathrm{N}=18)$ and contractor employees $(\mathrm{N}=50)$

\begin{tabular}{lccccc}
\hline Symptom & \multicolumn{2}{c}{ Company employees } & & \multicolumn{2}{c}{ Contractor employees } \\
\cline { 2 - 3 } \cline { 5 - 6 } & Yes & Work-related & & Yes & Work-related \\
& $N(\%)$ & $N(\%)$ & & $N(\%)$ & N (\%) \\
\hline Eye irritation & $6(33)$ & $2(11)$ & & $20(40)$ & $14(28)$ \\
Nasal irritation & $4(22)$ & $1(6)$ & & $17(34)$ & $10(20)$ \\
Throat irritation & $4(22)$ & $1(6)$ & & $13(26)$ & $7(14)$ \\
Headache & $6(33)$ & $4(22)$ & & $19(38)$ & $7(14)$ \\
Shortness of breath & $3(17)$ & $1(6)$ & & $8(16)$ & $1(2)$ \\
Cough & $2(11)$ & $0(0)$ & & $13(26)$ & $7(14)$ \\
Wheeze & $1(6)$ & $0(0)$ & & $7(14)$ & $2(4)$ \\
Nausea & $1(6)$ & $1(6)$ & & $5(10)$ & $1(2)$ \\
Dizziness & $2(11)$ & $1(6)$ & & $6(12)$ & $3(6)$ \\
Confusion & $2(11)$ & $1(6)$ & & $1(2)$ & $1(2)$ \\
Feeling faint & $0(0)$ & $0(0)$ & & $2(4)$ & $2(4)$ \\
Heart racing & $1(6)$ & $1(6)$ & & $5(10)$ & $1(2)$ \\
Skin irritation & $0(0)$ & $0(0)$ & & $9(18)$ & $7(14)$ \\
Irregular heart rhythm & $1(6)$ & $0(0)$ & & $1(2)$ & $0(0)$ \\
\hline
\end{tabular}

We grouped pharmacists and pharmacy technicians by employer and compared their responses to the symptom survey questions (Table 12). A greater percentage of contractor pharmacists/pharmacy technicians reported skin, eye, nose, and throat irritation and respiratory symptoms than company pharmacists/pharmacy technicians. 
Table 12. Health symptoms in the month before our visit among company $(\mathrm{N}=13)$ and contractor $(\mathrm{N}=37)$ pharmacists/pharmacy technicians

\begin{tabular}{|c|c|c|c|c|}
\hline \multirow[t]{2}{*}{ Symptom } & \multicolumn{2}{|c|}{$\begin{array}{l}\text { Company pharmacists and } \\
\text { pharmacy technicians }\end{array}$} & \multicolumn{2}{|c|}{$\begin{array}{l}\text { Contractor pharmacists and } \\
\text { pharmacy technicians }\end{array}$} \\
\hline & $\begin{array}{l}\text { Yes } \\
\mathrm{N}(\%)\end{array}$ & $\begin{array}{c}\text { Work-related } \\
\mathrm{N}(\%)\end{array}$ & $\begin{array}{l}\text { Yes } \\
N(\%)\end{array}$ & $\begin{array}{c}\text { Work-related } \\
\mathrm{N}(\%)\end{array}$ \\
\hline Eye irritation & $3(23)$ & $1(8)$ & $15(41)$ & $9(24)$ \\
\hline Nasal irritation & $2(15)$ & $0(0)$ & $13(35)$ & 7 (19) \\
\hline Throat irritation & $2(15)$ & $0(0)$ & $10(27)$ & $5(14)$ \\
\hline Headache & $4(31)$ & $3(23)$ & $13(35)$ & $5(14)$ \\
\hline Shortness of breath & $2(15)$ & $0(0)$ & $4(11)$ & $1(3)$ \\
\hline Cough & $2(15)$ & $0(0)$ & $8(22)$ & $5(14)$ \\
\hline Wheeze & $1(8)$ & $0(0)$ & $5(14)$ & $2(5)$ \\
\hline Skin irritation & $0(0)$ & $0(0)$ & $4(11)$ & $2(5)$ \\
\hline
\end{tabular}

We looked at the symptoms of nausea, dizziness, confusion, feeling faint, heart racing, and irregular heart rhythm reported by more than one employee in each job title. Contractor shippers/packers $(\mathrm{N}=13)$ were the only employee group to have more than one employee report dizziness (3) and feeling faint (2) that was better when away from work. No company or contractor pharmacist/pharmacy technicians reported these as work-related symptoms.

\section{Medical Record Review}

We reviewed medical records of four employees. Two employees' records documented symptoms of shortness of breath, but no diagnosis was given regarding these symptoms. One employee's record documented frequent severe headaches, but did not indicate an association with work exposures. The fourth employee's medical record documented an episode of headache and vomiting that began at work, but did not assess whether the symptoms were associated with work exposures. Overall, we saw no clear association between work exposures and the employees' symptoms or medical conditions. We focused our record review on symptoms that could be related to pharmaceutical dust exposure; we did not request records regarding musculoskeletal injuries or disorders.

\section{Occupational Safety and Health Administration Form 300 Log of Work-Related Injuries and IIIInesses Review}

We reviewed company and contractor OSHA Logs from 2009 through 2012. The most common entries in both company and contractor logs for all years were musculoskeletal injuries and disorders followed by lacerations, contusions, and abrasions. There was one entry for respiratory illness in 2009 and one entry for dermatitis in 2012. 


\section{Sampling Pharmaceutical Dust in Air and on Surfaces}

\section{Real-time Particle Concentrations}

Results of the real-time particle measurements are in Appendix B, Figures B1-B7. We used this information, along with comments provided by employees on the dustiness of different pharmaceutical tablets, to decide which APIs to measure in the air samples. These figures show peaks in particle number concentrations that correlated with events involving specific APIs. Refilling Baker machine canisters with uncoated tablets (Appendix B, Figures B1-B3) and cleaning automated counters with canned air in the manual count area (Appendix B, Figure B6) produced elevated airborne dust concentrations. However, the highest transient particle number concentrations (up to 39,000 particles per liter) were measured during the cleaning and repairing of Baker machine cells by an employee on second shift (Appendix B, Figure B4). An employee who did this task on first shift (Appendix B, Figure B5) also generated airborne dust (up to 8,000 particles per liter). These employees wore vinyl gloves but no other personal protective equipment or clothing. Emptying uncoated tablets from cells into bins and returning those tablets back to the cells (after cleaning or repairing the cells) produced the most airborne dust. Most of the particles released during cleaning and repairing of cells were $>10$ micrometers $(\mu \mathrm{m})$ in aerodynamic diameter. Conversely, most of the particles produced when an employee cleaned the automated counter with canned air were $<1 \mu \mathrm{m}$ in aerodynamic diameter. Particles 0.3 to $>10 \mu \mathrm{m}$ in aerodynamic diameter were produced when refilling canisters.

\section{Air Concentrations of Inhalable Dust, Lactose, and Active Pharmaceutical Ingredients}

The full-shift ( $~ 8$ hours) personal and area air sample concentrations of inhalable dust are summarized in Figure 3. The full-shift personal and area air concentrations of lactose (inactive filler in tablets) are summarized in Figure 4. Values that were not detectable (ND) in the bar graphs were assigned values created by dividing the minimum detectable concentrations (MDCs) by the square root of two. The MDCs and minimum quantifiable concentrations (MQCs) were calculated by dividing the analytical limits of detection and quantitation (mass units) for each analyte by the average volume of air sampled. The MDCs and MQCs represent the lowest air concentrations that could have been detected (MDC) or quantified (MQC) and are provided in Appendix C, Figure $\mathrm{C} 1$ for each analyte. 
The personal air concentrations are more informative than the area air concentrations because they represent what employees could inhale. The highest average personal inhalable dust concentrations were measured on employees in the bulk/hazardous drug area and Baker refill area, as well as on the housekeeping employees. The highest maximum personal inhalable dust concentrations were measured on employees in the Baker maintenance and refill areas. The highest average and maximum personal lactose concentrations were measured on employees who worked in the Baker maintenance and refill areas. The background area air concentrations of lactose measured in the offices were significantly less than the area air concentrations of lactose measured in the production areas (two-sample t-test; $P=0.035$ ) and the personal air concentrations of lactose measured on employees who worked in the production areas (two-sample t-test; $P=0.029$ ). This finding suggests that pharmaceuticals were the main source of airborne lactose (minimal outside sources).

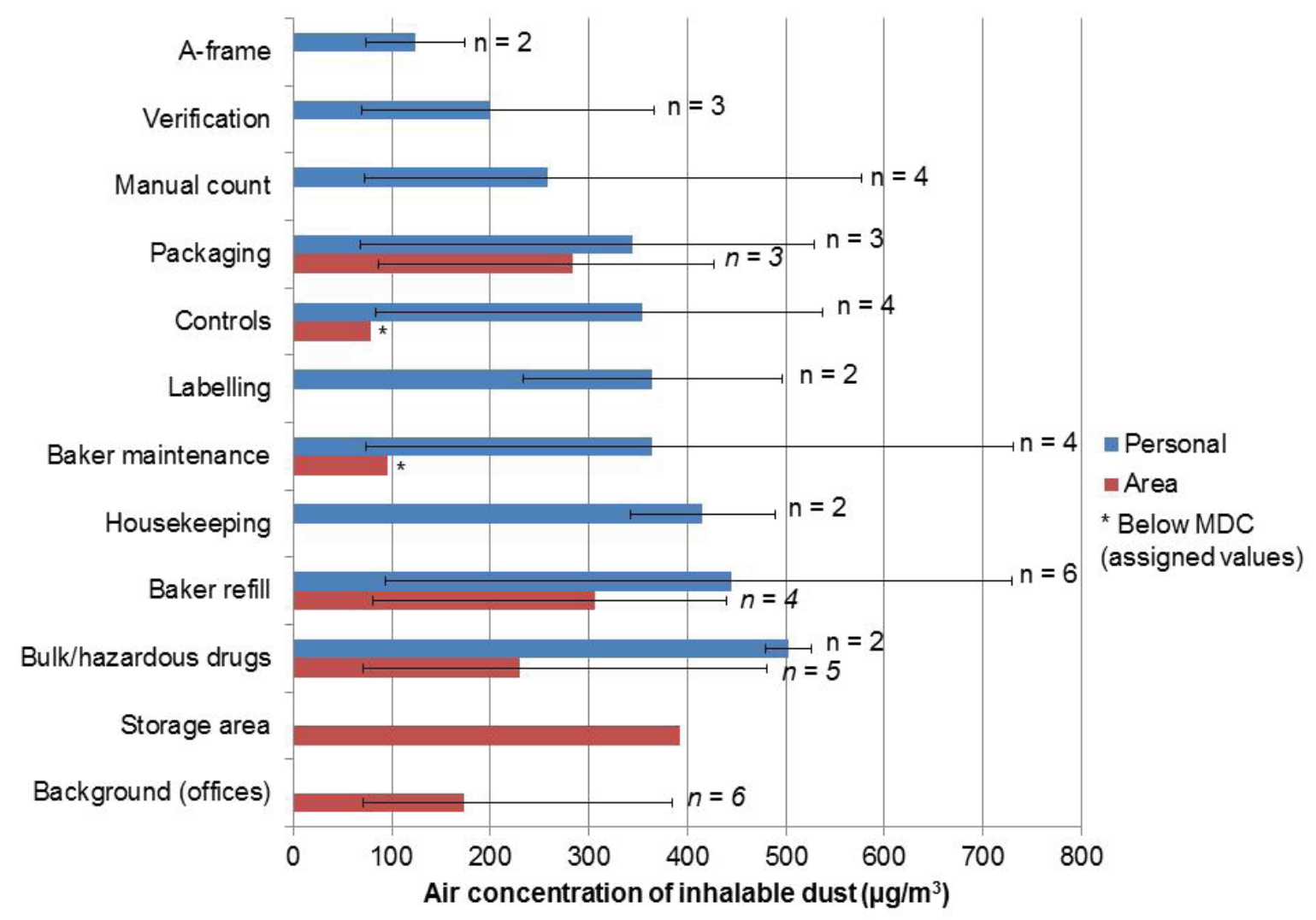

Figure 3. Average full-shift personal and area air concentrations of inhalable dust by process or work area. The number of samples and error bars representing the minimum and maximum concentrations are provided if more than one sample was collected. 


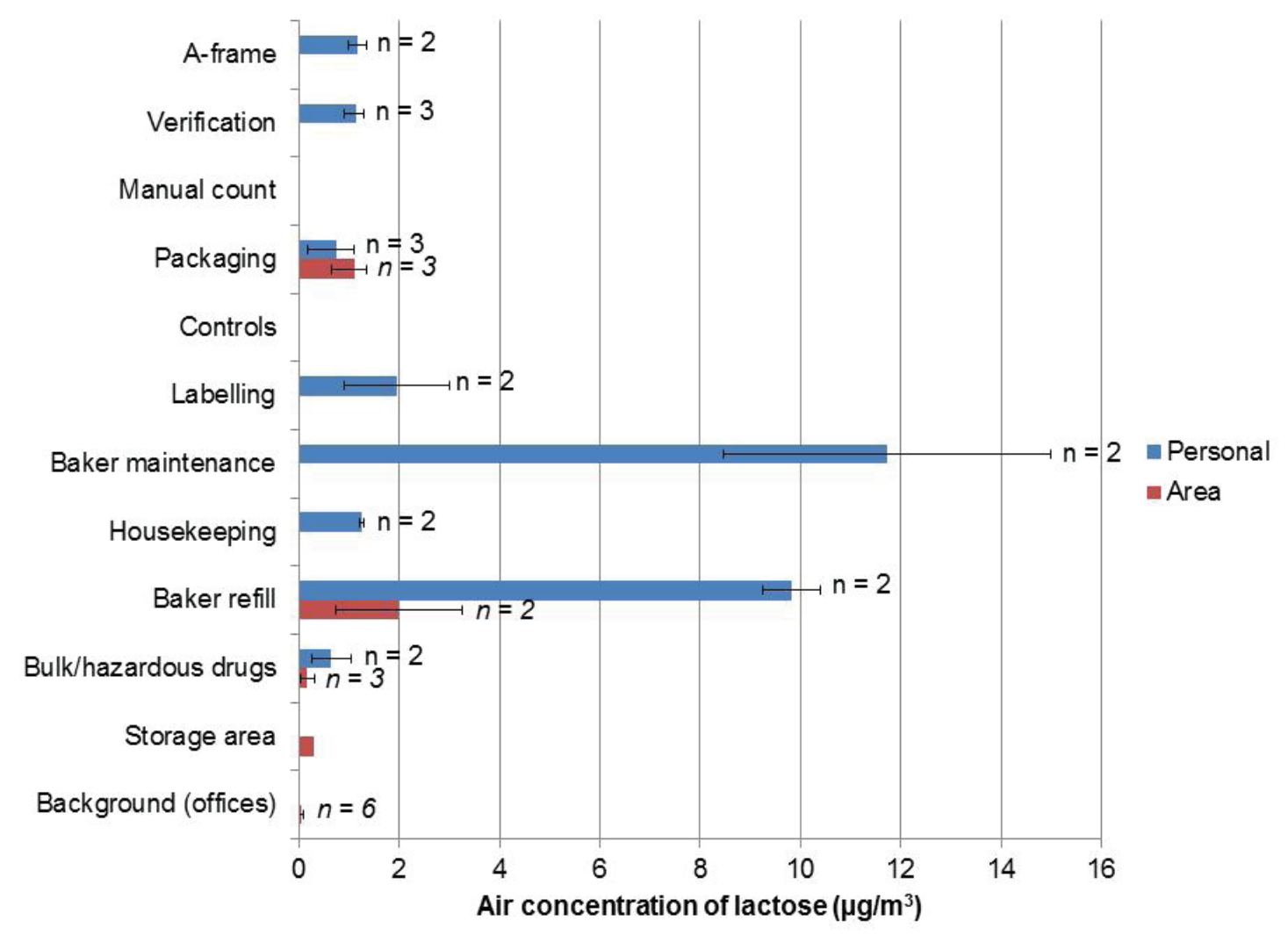

Figure 4. Average full-shift personal and area air concentrations of lactose by process or work area. The number of samples and error bars representing the minimum and maximum concentrations are provided if more than one sample was collected.

In addition to the full-shift air samples, we collected a task-based (20-minute) personal air sample on a housekeeping employee emptying a wet/dry vacuum (day 3 ). This sample measured no inhalable dust $\left(<\right.$ MDC of 2,400 micrograms per cubic meter $\left.\left[\mu \mathrm{g} / \mathrm{m}^{3}\right]\right)$ and $40 \mu \mathrm{g} / \mathrm{m}^{3}$ of lactose. This level of lactose suggests that some pharmaceutical dust was released into the air where it could be inhaled during this task. The slightly elevated realtime particle measurements during this task (Appendix B, Figure B5) provide additional support for this conclusion. The housekeeping employee wore nitrile gloves and a NIOSHapproved N95 filtering facepiece respirator (Honeywell/Wilson Saf-T-Fit Plus) during this task; however, we observed that the respirator did not seal properly around the employee's face. We also collected a personal air sample on an employee who hand-filled prescriptions in the manual count area during second shift (day 2). This sample was collected for only part of the shift (260 minutes) and measured $810 \mu \mathrm{g} / \mathrm{m}^{3}$ of inhalable dust and $5.2 \mu \mathrm{g} / \mathrm{m}^{3}$ of lactose during that time period. 
Figure 5 summarizes the full-shift personal and area air concentrations of specific APIs measured in the Baker refill area. The background air concentrations of lisinopril and HCTZ measured in the office areas are also provided for comparison. We compared the personal air concentrations to published manufacturers' OELs or the lower bound of published manufacturer's hazard control bands (Appendix D, Table D1). All air concentrations were below these limits except for one area air concentration of lisinopril $\left(1.1 \mu \mathrm{g} / \mathrm{m}^{3}\right)$. This area air sample was collected above the canister of HCTZ/lisinopril tablets. Although this sample does not represent personal exposure, it does indicate that lisinopril dust was released into the work environment. Personal air concentrations of lisinopril, however, were all ND (same as background levels).

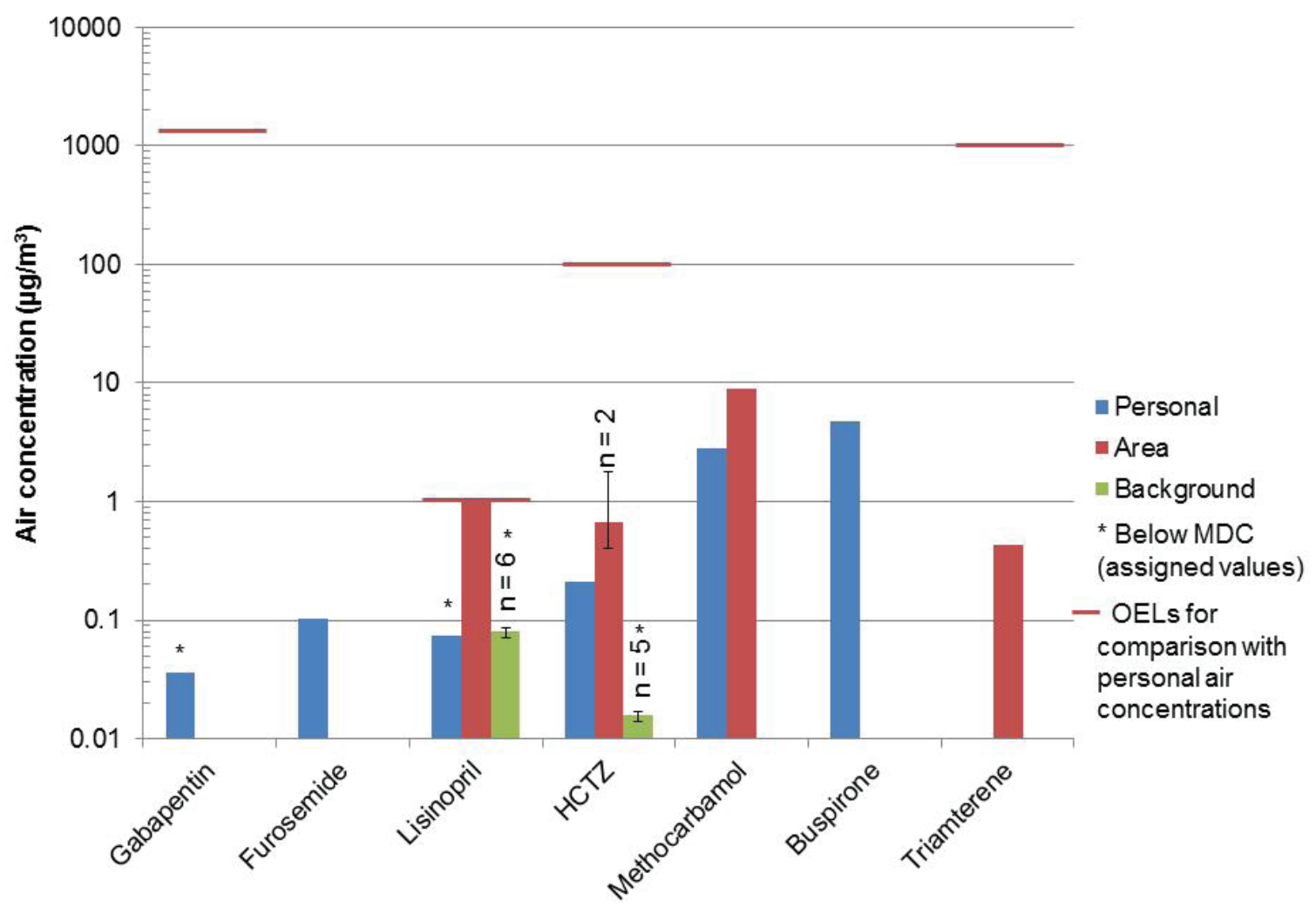

Figure 5. Average full-shift personal and area air concentrations of specific APIs measured in the Baker refill area. Background area air concentrations of lisinopril and HCTZ (measured in the offices) are also provided. The number of samples and error bars representing the minimum and maximum concentrations are provided if more than one sample was collected. 
Figure 6 presents the full-shift personal and area air concentrations of specific APIs measured in the Baker maintenance area. Dust containing these APIs was released when cells were cleaned. The personal air concentration of naproxen was below the manufacturer's OEL [Roche 2006]. The manufacturer's hazard control band for levothyroxine is $<1 \mu \mathrm{g} / \mathrm{m}^{3}$ [Pfizer 2011]; hence, the arrows in the figure indicate a lower bound of the hazard control band somewhere below $1 \mu \mathrm{g} / \mathrm{m}^{3}$. Because most hazard control bands established by pharmaceutical manufacturers span one order of magnitude, a lower bound of $0.1 \mu \mathrm{g} / \mathrm{m}^{3}$ may be reasonable for evaluating exposure. All air concentrations of levothyroxine were below $0.1 \mu \mathrm{g} / \mathrm{m}^{3}$.

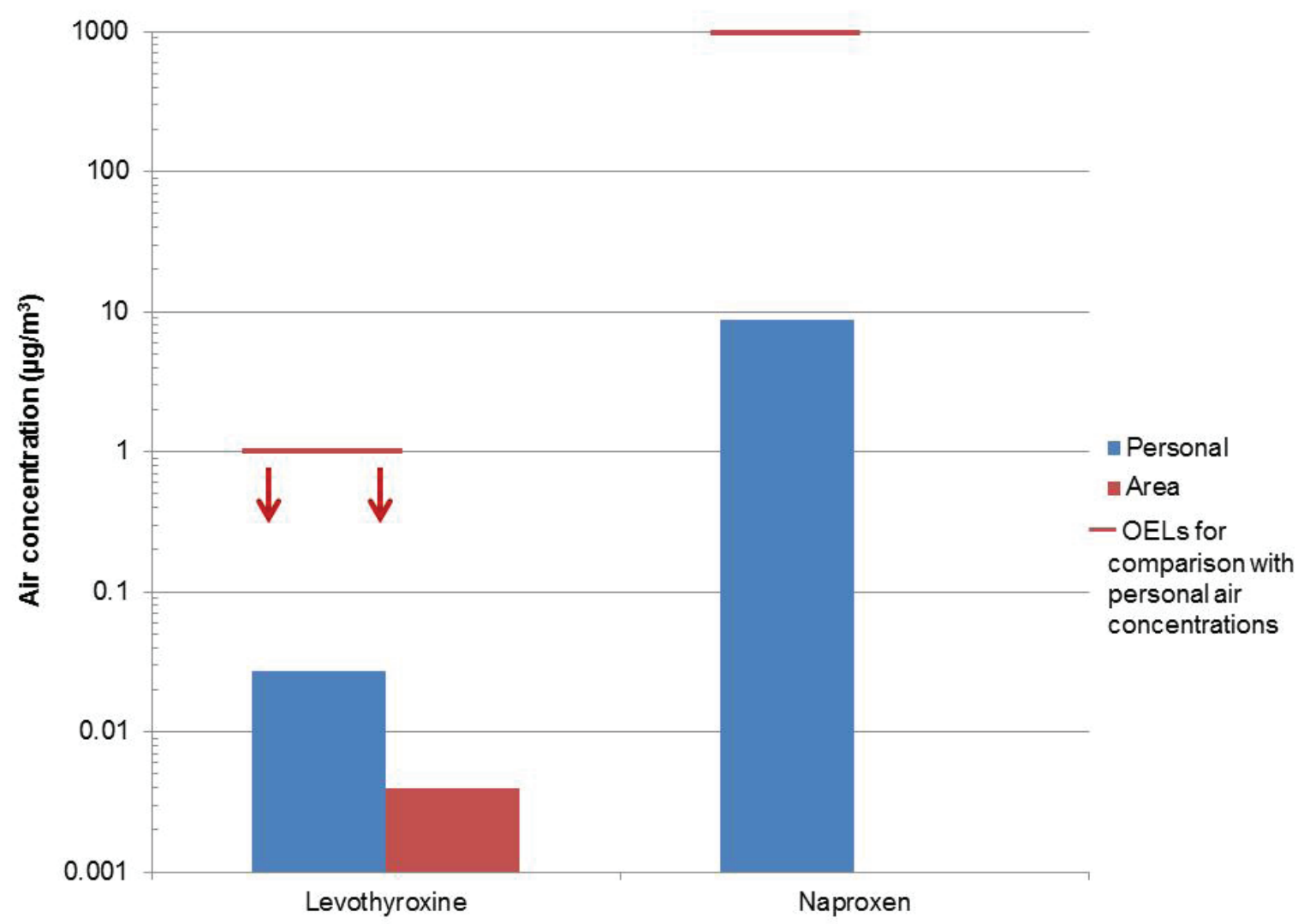

Figure 6. Full-shift personal and area air concentrations of levothyroxine and naproxen measured in the Baker maintenance area. 
The full-shift personal and area air concentrations of hydrocodone measured in the controls area are summarized in Figure 7. All air concentrations were below the manufacturer's OEL of $5 \mu \mathrm{g} / \mathrm{m}^{3}$ [Abbott Labs 2011].

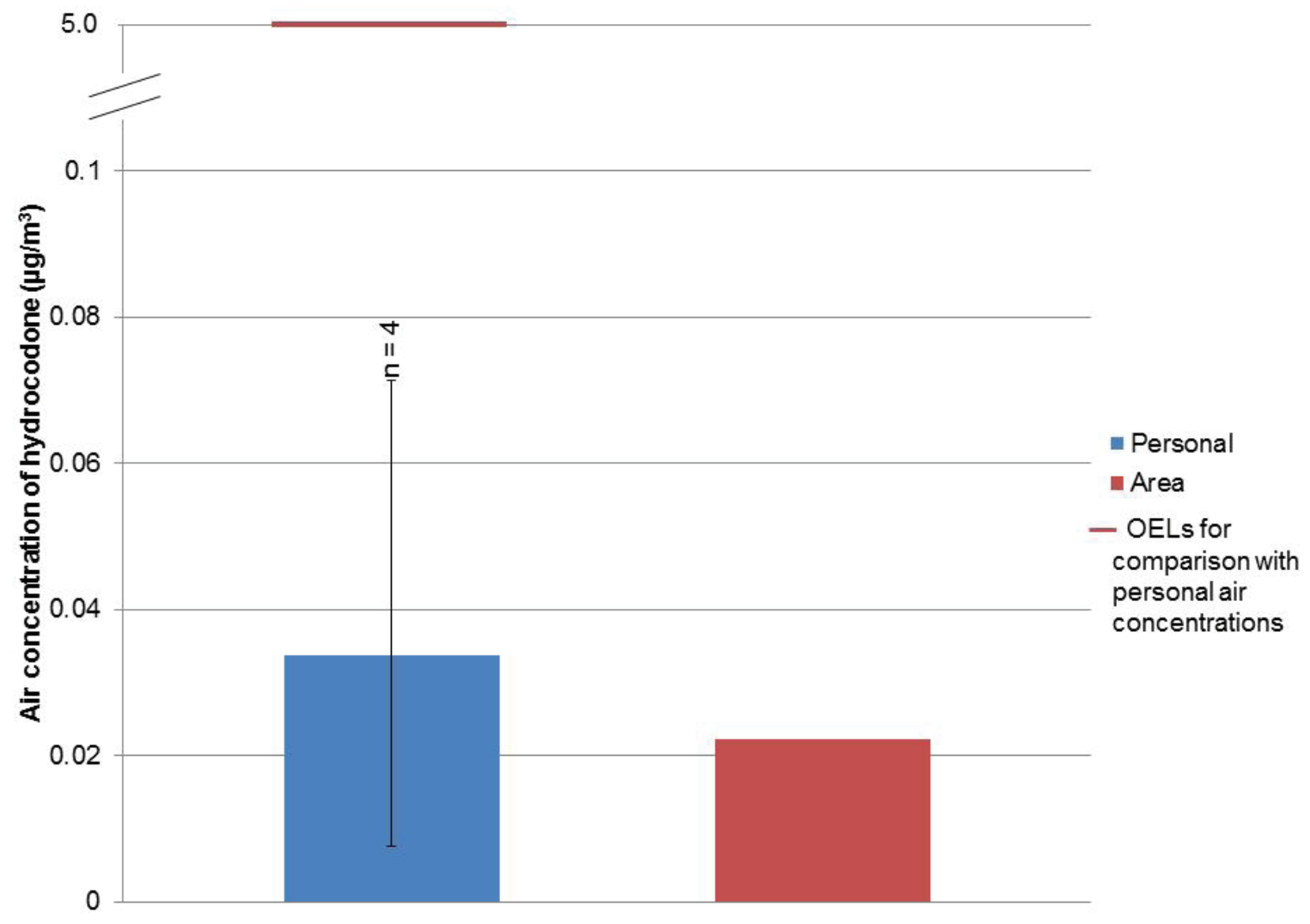

Figure 7. Average full-shift personal and area air concentrations of hydrocodone measured in the controls area. The number of samples and error bars representing the minimum and maximum concentrations are provided if more than one sample was collected.

Employees' exposures to multiple APIs (during a single work shift) cannot be seen in the bar graphs. The results from sampling multiple APIs in three employees' personal breathing zones are therefore provided in Table 13. The Baker maintenance employee on second shift was only sampled for part of the shift. This employee's personal air concentration of lisinopril during the sampled period was above the lower bound of the manufacturer's hazard control band [Bristol-Myers Squibb Company 2012b]. Assuming zero exposure for the unsampled time period is not appropriate because this employee continued to do tasks that could release pharmaceutical dust (e.g., clean cells). However, even if no other lisinopril exposure occurred for the rest of the shift, this employee's 8-hour time-weighted average $\left(1.5 \mu \mathrm{g} / \mathrm{m}^{3}\right)$ would still exceed the manufacturer's OEL. All other personal air concentrations were below applicable manufacturer's OELs. 
Table 13. Results from sampling multiple APIs in an employee's personal breathing zone

\begin{tabular}{|c|c|c|c|c|c|c|c|c|c|}
\hline \multirow{2}{*}{$\begin{array}{l}\text { Process } \\
\text { description }\end{array}$} & \multirow{2}{*}{$\begin{array}{c}\text { Sample } \\
\text { no.* }\end{array}$} & \multirow{2}{*}{$\begin{array}{l}\text { Sample } \\
\text { time } \\
\text { (min) }\end{array}$} & \multicolumn{7}{|c|}{ Personal air concentration $\left(\mu \mathrm{g} / \mathrm{m}^{3}\right)$} \\
\hline & & & 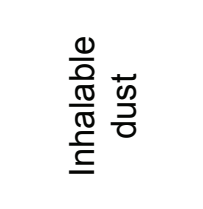 & $\begin{array}{l}\mathscr{D} \\
\stackrel{0}{0} \\
\stackrel{0}{0} \\
\Xi\end{array}$ & 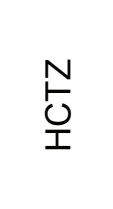 & 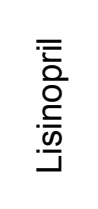 & 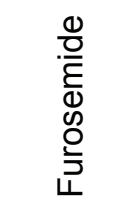 & 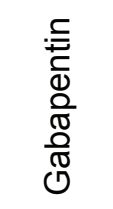 & 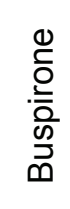 \\
\hline $\begin{array}{l}\text { Baker refill, } \\
\text { day } 1, \\
\text { first shift }\end{array}$ & 13/17† & 481 & ND-370 & NA & NA & NA & NA & ND & ND \\
\hline $\begin{array}{l}\text { Baker refill, } \\
\text { day } 2 \text {, } \\
\text { first shift }\end{array}$ & $25 / 40 \dagger$ & 481 & $(330) \S-490$ & 9.2 & 0.21 & ND & $(0.10) \S$ & NA & NA \\
\hline $\begin{array}{l}\text { Baker } \\
\text { maintenance, } \\
\text { day } 2 \text {, } \\
\text { second shift }\end{array}$ & 21 & 279 & 1,600 & 67 & 36 & 2.5 & NA & NA & NA \\
\hline MDC $\ddagger$ & & & 100 & 0.003 & 0.02 & 0.1 & 0.05 & 0.05 & 5 \\
\hline MQC $\ddagger$ & & & 470 & 0.01 & 0.065 & 0.36 & 0.18 & 0.18 & 18 \\
\hline $\begin{array}{l}\text { Manufacturer } \\
\text { OEL or hazard } \\
\text { control band }\end{array}$ & & & NA & NA & 100 & $1-10$ & NA & 1,200 & 10 \\
\hline
\end{tabular}

*Sample numbers are provided for cross-referencing with the figures in Appendix B.

†Side-by-side personal air samples were collected.

$¥ M D C$ and MQC provided were based on 8 hours of sampling.

$\S$ Values between the MDC and MQC are shown in parentheses to point out that there is more uncertainty associated with these values than with concentrations above the MQC.

THCTZ [Bristol-Myers Squibb Company 2012a], Lisinopril [Bristol-Myers Squibb Company 2012b], Gabapentin [Pfizer 2010], Buspirone [U.S. Pharmacopeia 2006]. More information on the manufacturer's OELs is provided in Appendix D.

\section{Air Concentrations of Hazardous Drugs}

Of the 32 hazardous drugs dispensed as tablets at the pharmacy, we only observed the filling of methotrexate prescriptions. Appendix B, Figure B7 shows the real-time particle measurements near the breathing zone of the employee who filled methotrexate prescriptions (day 1). These measurements do not show particle levels above background while methotrexate tablets were being handled. However, methotrexate dust was measured in two full-shift area air samples collected during this workday. The area air sample positioned near the employee who hand-filled the methotrexate prescriptions measured $0.008 \mu \mathrm{g} / \mathrm{m}^{3}$ of methotrexate. A fan on the wall behind this employee produced a current of air through the hazardous drug area that could transport pharmaceutical dust to other workstations. The area air sample that was positioned downwind at a pharmacy technician's workstation measured $0.0003 \mu \mathrm{g} / \mathrm{m}^{3}$ of methotrexate. A personal air sample was collected on an employee who hand-filled methotrexate prescriptions during second shift (day 2) and methotrexate was ND $\left(<0.0006 \mu \mathrm{g} / \mathrm{m}^{3}\right)$. However, this sample only ran for 94 minutes because this employee 
was moved to a different area shortly after starting the shift. All of these air concentrations were more than an order of magnitude below the manufacturer's OEL of $0.3 \mu \mathrm{g} / \mathrm{m}^{3}$ [U.S. Pharmacopeia 2013b].

\section{Surface Contamination Levels of Lactose and Active Pharmaceutical Ingredients}

Table 14 gives the levels of lactose and hydrocodone measured on surfaces in the pharmacy. We sampled in the offices to estimate background contamination. Levels of lactose measured on surfaces in the offices were below the levels measured on surfaces in the Baker machine area. Hydrocodone was detected at each sampled workstation in the controls area. In addition, eight surface samples were collected in the hazardous drug area for methotrexate. All were ND $\left(<0.001 \mu \mathrm{g} / \mathrm{m}^{3}\right)$ except for a sample collected from the workstation of the employee who filled methotrexate prescriptions (day 1). This sample was collected before the employee cleaned the surface with isopropyl alcohol wipes. Two other surface samples were collected in the Baker refill area on surfaces where dust had accumulated. One of these samples measured $2.8 \mu \mathrm{g} / 100 \mathrm{~cm}^{2}$ of glipizide on the shelf below a canister of glipizide; the other sample measured $6,900 \mu \mathrm{g} / 100 \mathrm{~cm}^{2}$ of methocarbamol above the canister containing this drug.

Table 14. Surface contamination levels $\left(\mu \mathrm{g} / 100 \mathrm{~cm}^{2}\right)$ of lactose and hydrocodone

\begin{tabular}{llcc}
\hline General location & Specific location & Lactose & Hydrocodone \\
\hline Background & Administrative office desk & $(0.04)^{*}$ & NA \\
& Fiscal office desk & $(0.03)^{*}$ & NA \\
& Procurement office desk & $(0.02)^{*}$ & NA \\
& Sign-in podium in entrance & $(0.02)^{*}$ & NA \\
& Workstation surface between monitors & 0.79 & NA \\
& Electrical box near pharmacist verification station & 1.2 & NA \\
& Electrical box near exhaust hood & 8.5 & NA \\
& A-frame near the machine & 18 & NA \\
& Above primidone canister & 3.7 & NA \\
& CT1 workstation & NA & 3.2 \\
& CT3 workstation & NA & 1.9 \\
& CT4 workstation/cart lower shelf & NA & $(1.3)^{*}$ \\
\hline Detection limit & & 0.02 & 0.5 \\
Quantitation limit & & 0.06 & 1.7 \\
\hline
\end{tabular}

*Values between the detection limit and quantitation limit are shown in parentheses to point out that there is more uncertainty associated with these values than with levels above the quantitation limit.

\section{Other Observations and Findings}

Employees demonstrated good housekeeping and hand-washing practices. Employees cleaned their workstations periodically throughout the day, typically using isopropyl alcohol wipes. The housekeeping employees cleaned surfaces (e.g., sweeping and vacuuming) and emptied trash throughout the day. During the first shift, the employees we observed washed their hands before eating during their lunch break. 
Protective clothing and eyewear were not required or provided to employees in any areas of the pharmacy. Most employees wore vinyl gloves when handling pharmaceuticals as required by the employer and when cleaning surfaces with isopropyl alcohol wipes. We observed no employees voluntarily wearing hearing protection, but we did observe a housekeeping employee voluntarily wearing an N95 filtering facepiece respirator when emptying the bag in the wet/dry vacuum. We saw white dust on a black shirt of a Baker machine maintenance employee after this employee cleaned several cells. This dust likely was from the pharmaceuticals. This employee did not use the exhaust hood even though the standard operating procedures required its use.

We observed one Baker maintenance employee using the exhaust hood when cleaning a cell. The exhaust hood effectively captured airborne dust released when this employee HEPA vacuumed the cell inside the hood. However, the employee emptied and refilled the cell outside the hood. The hood did not appear large enough to accommodate these tasks, which our data suggest have potential to produce airborne pharmaceutical dust.

\section{Discussion}

Overall, employees had a positive perception of safety climate. However, contractor pharmacists and pharmacy technicians had less favorable views of safety training and the amount of risk employees are exposed to when compared to company employees with the same job titles. These differences should be explored further to determine what causes the difference in perception between contractor and company employees, and whether the issues are related (e.g., is the perception of risk greater for contractor employees due to gaps in training?).

A common theme reported by contractor employees was that the work attendance policy is associated with job stress and a strain on employer-employee relations. Contractor employees reported being penalized for staying home if they were ill, even if their illness was serious, and they had a doctor's note. Only five (10\%) contractor employees reported that they were comfortable staying home if they were ill. The punitive attendance system encourages presenteeism, which is defined as "attending work while ill" [Johns 2010]. Presenteeism is associated with productivity loss [Schultz and Edington 2007] and the spreading of contagious illnesses throughout the workplace [Widera et al. 2010]. Some studies have shown that presenteeism results in as much if not more costs than absenteeism [Stewart et al. 2003; Cooper and Dewe 2008].

Of the 22 employees who described a poor employer-employee relationship, 14 (64\%) specifically mentioned the point system for punishing illness absences when describing the relationship. While the attendance policy appears to play a role in contractor employees' reports of a strained relationship with their supervisor, other factors should also be further explored to determine the nature of the interpersonal conflict. Interpersonal conflict at work is associated with greater levels of stress, psychosomatic complaints, and burnout among employees [De Dreu et al. 2003]. 
Contractor employees with the job title of shipper/packer reported the greatest amount of concern about exposures at work impacting their health. These employees also reported the greatest amount of job stress compared to employees with other titles. These findings warrant further investigation to determine what factors are associated with shippers/packers' perceptions of job stress and work-related health concerns.

Pharmaceutical dust can irritate the eyes, nose, throat, and skin. Our medical assessment found higher percentages of contractor employees reporting respiratory symptoms and eye, nasal, throat, and skin irritation that were associated with work than company employees. This is likely due to contractors performing job tasks with higher potential pill dust exposures. Two contractor employees reported developing asthma-like symptoms since being hired. Although medical records did not document asthma as a diagnosis, patients with asthma may have intermittent bronchial hyperreactivity and not exhibit symptoms at the time of medical evaluation. Other employees with pre-existing asthma reported increased symptoms at work, and one employee reported developing hives when working near the Baker machine. These employees may have developed sensitization to certain pharmaceutical dusts. Pharmaceutical dust exposures may elicit allergic respiratory and skin symptoms in sensitive individuals, potentially resulting in allergic medical conditions such as allergic asthma, rhinitis, urticaria (hives), and contact dermatitis [Teichman et al. 1988; Bernstein et al. 1999; Heron and Pickering 2003; Zuskin et al. 2004].

About one fourth of employees reported concerns about prolonged standing and repetitive, forceful motions using extreme postures. Musculoskeletal disorders are conditions that involve the soft tissues, including the nerves, tendons, and muscles. They can be characterized by intermittent pain which can restrict mobility and interfere with normal activity. Work-related musculoskeletal disorders refer to musculoskeletal disorders to which the work environment and the performance of work contribute significantly or are made worse by work conditions. A substantial body of data provides strong evidence of an association between musculoskeletal disorders and certain work-related factors (physical, work organizational, psychosocial, individual, and sociocultural). Personal factors can also influence the response to risk factors for musculoskeletal disorders; these personal factors include age, sex, smoking, physical activity, strength, and body measurements such as height and weight. Although personal factors may affect an individual's susceptibility to overexertion injuries/disorders, studies in highrisk industries show that the risk associated with personal factors is small compared to that associated with occupational exposures [NIOSH 1997a]. In all cases, the preferred method for preventing and controlling musculoskeletal disorders is to design jobs, workstations, tools, and other equipment to match the physiological, anatomical, and capabilities of the employee. Under these conditions, exposures to risk factors considered potentially hazardous are reduced or eliminated.

Cleaning automated counters with canned air in the manual count area, refilling canisters, and cleaning and repairing cells in the Baker machine area correlated with peaks in realtime particle number concentrations. The emptying and refilling of cells during the cleaning and repairing process (second shift, day 2) produced the largest increase in particle number concentrations. Particles of various sizes were measured $(0.3$ to $>10 \mu \mathrm{m}$ in aerodynamic 
diameter); the predominant particle size produced depended on the task. For example, most particles produced during the cleaning and repairing of cells were $>10 \mu \mathrm{m}$ in aerodynamic diameter; while most particles produced when an employee cleaned the automated counter with canned air were $<1 \mu \mathrm{m}$ in aerodynamic diameter. In an evaluation at an outpatient pharmacy, we found that mostly small particles $(<3 \mu \mathrm{m})$ were generated when compressed air was used to clean canisters [NIOSH 2013a]. Thus, it appears that using canned or compressed air to clean pharmaceutical equipment can produce a greater portion of small particles than what other common tasks (e.g., refilling cells or canisters) produce. Particles $<3 \mu \mathrm{m}$ in diameter remain airborne longer than particles $>10 \mu \mathrm{m}$ in diameter (hours versus minutes) and are capable of penetrating deeper into the lungs.

Our inhalable dust air samples collected particles that can be deposited anywhere in the respiratory system, including the nose and mouth. These particles range from $<1 \mu \mathrm{m}$ to $>100 \mu \mathrm{m}$ in aerodynamic diameter. Measuring inhalable dust is appropriate for pharmaceutical exposure assessments because many APIs are water soluble and can be absorbed anywhere in the respiratory system, including nasal passages. The inhalable dust concentrations provide a relative indication of the areas that are the dustiest. However, inhalable dust is not specific to pharmaceuticals because it can include dust from other sources. That we found lactose (an inactive filler in tablets) in significantly higher air concentrations in the production areas compared to the nonproduction areas suggests that pharmaceuticals were the main source of lactose. Average concentrations of lactose were highest in the personal breathing zones of employees in the Baker maintenance and refill areas. Employees in these areas also had the highest maximum personal air concentrations of inhalable dust.

Most APIs do not have OELs set by federal agencies or national organizations. Because pharmaceuticals are biologically active and typically water soluble, OELs for nuisance dusts or "particles not otherwise specified" do not apply [ACGIH 2013]. Thus, when available, we used manufacturers' OELs for comparing our results. Pharmaceutical manufacturers establish OELs or hazard control bands primarily using a control banding process. Appendix D provides more information on control banding. All personal air concentrations of APIs were below manufacturer's OELs, except for the personal air concentration of lisinopril measured on the Baker maintenance employee during second shift (day 2). Possible acute health effects from high exposures to lisinopril listed on the safety data sheet included dizziness, headache, and allergic reactions [Bristol-Myers Squibb Company 2012b]. Maintaining airborne lisinopril exposures below the manufacturer's OEL should prevent these health effects in most employees. Although a Baker maintenance employee's exposures to levothyroxine were below the manufacturer's hazard control band upper bound (no lower bound was provided), the safety data sheet specifically recommends that "All operations should be fully enclosed [with] no air recirculation permitted" [Pfizer 2011]. This employee cleaned the cell that housed levothyroxine outside of the exhaust hood. The exhaust hood recirculated air through a HEPA filter.

Methotrexate was the only hazardous drug we observed being dispensed, and hence, the only hazardous drug we sampled in air. The health risk from hazardous drugs depends 
on how much exposure an employee has to these drugs and how toxic they are [NIOSH 2004]. Methotrexate has been shown to cause birth defects in infants of women who took therapeutic doses of the drug while pregnant [Lloyd et al. 1999; Pfizer 2012]. However, the therapeutic dose of methotrexate (milligram levels) is substantially higher than the dose that would typically be obtained from working with the drug in a pharmacy (microgram levels) especially if workplace exposures are kept below the manufacturer's OEL. We found quantifiable levels of methotrexate in air near two employees who worked in the hazardous drug area. Although these were not personal air samples, they indicate a potential for inhalation exposure. However, both of these air concentrations were more than an order of magnitude below the manufacturer's OEL [U.S. Pharmacopeia 2013b]. Even lower exposures are expected if employees use engineering controls. The safety data sheet for methotrexate recommends that employees "Use a laboratory fume hood, vented enclosure, glove box, or other effective containment” [U.S. Pharmacopeia 2013b].

NIOSH considers pharmaceuticals to be hazardous drugs when they exhibit one or more of the following characteristics in humans or animals: (1) carcinogenicity, (2) teratogenicity (toxic effects to the fetus in utero), (3) reproductive effects (infertility), (4) organ toxicity at low doses, (5) genotoxicity (chromosomal mutations), and (6) have structures and toxicity profiles that mimic existing hazardous drugs [NIOSH 2012]. Exposure to APIs not classified as hazardous are still capable of producing a biological effect in the body that may result in adverse health effects [Teichman et al. 1988; Heron and Pickering 2003]. For example, it is possible that substantial exposure to high blood pressure medication dust can lead to low blood pressure in some employees and could result in symptoms of dizziness and headaches [Bristol-Myers Squibb Company 2012b]. Headaches were reported in about one third of company and contractor employees; however, headaches are very common in the general population, and their cause is often difficult to determine. There was no evidence gathered during our evaluation that headaches reported by employees were related to exposure to high blood pressure medication dust. No employees reported miscarriages, infertility problems, giving birth to a child with birth defects, or being diagnosed with cancer or immunodeficiency disorders since being hired to work at this facility.

The thyroid gland produces hormones that help regulate the body's metabolism, that is, the rate of many activities in the body. A thyroid working correctly will produce the right amount of hormones needed to keep the body's metabolism working at a rate that is not too fast or too slow. When it is not working correctly, the thyroid can produce more hormones than it needs (hyperthyroidism) or much less than it needs (hypothyroidism). Hyperthyroidism and hypothyroidism can be caused by hereditary factors, autoimmune disorders, an excess or deficiency of iodine, and prior radiation treatment, but some causes remain unknown. Hypothyroidism is fairly common in the United States, occurring in close to $5 \%$ of the population. Hypothyroidism is more common among women, whites, and Latinos [Ladenson and Kim 2008]. Hyperthyroidism is less common, with a lifetime prevalence of $1 \%$. The rates of reported thyroid disorders among interviewed employees appear high when compared to the general population; however, comparing a working group with very small numbers to the general population in the U.S. is neither reliable nor accurate. Rates are highly variable in small populations (such as a workplace) and rarely match the overall rate for a larger 
area, such as a state, so that for any given time period some populations have rates above the overall rate and others have rates below the overall rate. So, even when a higher rate occurs, this may be completely consistent with the expected random variability. Although exposure to some APIs (e.g., levothyroxine) could affect normal thyroid function, six of the eight cases of known thyroid conditions reported by the employees were hypothyroidism, which would not have been related to levothyroxine exposures.

Our sampling results demonstrate that employees can be exposed to dust that contains hazardous drugs. If hazardous drugs continue to be filled the same way, the potential for overexposures will depend on the dustiness of the tablets, formulation of the tablets (percentage of tablets that is the hazardous drug), and how many prescriptions are filled. Even if no overexposures to hazardous drugs occur, reducing exposures as much as feasible is prudent and encouraged in the NIOSH Alert, "Preventing Occupational Exposure to Antineoplastic and Other Hazardous Drugs in Health Care Settings" [NIOSH 2004].

Our finding of air concentrations of APIs below manufacturer's OELs for most of the processes does not necessarily mean that employees are adequately protected all the time. We were not able to quantify all possible API exposures primarily because of laboratory analytical limitations, and not all the quantified APIs had published manufacturer's OELs for comparison. Also, the air samples we collected over a 3-day period may not be representative of exposures throughout the year because exposures can vary over time. In addition, our sampling results demonstrated that some employees (i.e., one who refilled Baker machine canisters and one who maintained the Baker machine) were exposed to multiple APIs during their workday. Additive or synergistic effects from multiple API exposures are possible but not well understood.

The surface sampling results indicate that pharmaceutical dust deposits onto surfaces in the four areas where we focused our sampling: Baker maintenance, Baker refill, controls, and hazardous drugs. Specific APIs were detected on work surfaces used when filling prescriptions (e.g., hydrocodone and methotrexate) and on surfaces near where canisters were refilled (e.g., methocarbamol and glipizide). The presence of lactose, although not specific to any particular API, suggests the presence of APIs; no other sources of lactose existed in this environment. These results also indicate a potential for skin or clothing contamination. We observed suspected pharmaceutical dust on one employee's shirt after this employee cleaned several canisters. Such contamination of skin or clothing could lead to hand-tomouth ingestion of pharmaceuticals during eating or smoking and to take-home exposure. Children at home may be especially susceptible to adverse health effects from API exposures [Brent et al. 2004]. These results, therefore, underscore the importance of having adequate housekeeping and hand-washing practices, and wearing protective clothing and eyewear in these areas at least until engineering controls are implemented and shown to be effective at reducing employee exposures and work surface contamination to the lowest feasible levels. The pharmacy employees demonstrated good housekeeping and hand-washing practices, but none of the employees were provided or otherwise wore protective clothing or eyewear. 
We identified a few deficiencies related to the personal protective equipment and engineering controls used at the pharmacy. Our observation of one employee's use of the N95 filtering facepiece respirator suggests a need for retraining on how to select the appropriate size of respirator and how to adjust the respirator to seal properly around the face. Vinyl gloves were worn by most employees when handling pharmaceuticals or when cleaning surfaces or equipment with isopropyl alcohol wipes. However, nitrile gloves are more resistant than vinyl gloves to isopropyl alcohol [Forsberg and Mansdorf 2007]. If isopropyl alcohol were to permeate through vinyl gloves, it could deliver APIs on the gloves to the skin underneath. This route of exposure is of special concern for employees who handle cytotoxic or other hazardous drugs because these drugs can damage the skin or, in some cases, absorb through the skin and become systemically available. Compared to vinyl gloves, the neoprene gloves provided in the hazardous drug spill kits are resistant to far more chemicals [Forsberg and Mansdorf 2007]. However, neoprene gloves have not been tested against liquid hazardous drugs. Employees who unpacked drug shipments, including hazardous drugs, did not always wear gloves. Investigators in other studies have found contamination on the outside of vials containing antineoplastic drugs [Connor et al. 2005; Schierl et al. 2010]. Although not part of our evaluation, some pharmaceutical bottles could be contaminated with APIs. Therefore, employees should wear nitrile gloves when unpacking pharmaceutical shipments, especially hazardous drug shipments. Likewise, employees should wear nitrile gloves when handling prescription bottles filled with hazardous drugs. Although cleaning and repairing Baker machine cells produced among the highest levels of particle number concentrations, inhalable dust, lactose, and certain APIs (e.g., lisinopril), we observed only one Baker maintenance employee using the recirculating exhaust hood for cleaning and repairing cells. More Baker maintenance employees may have used the recirculating exhaust hood had it been large enough to accommodate all the cleaning tasks.

\section{Conclusions}

The system of penalizing contractor employees for not reporting to work when ill could have negative effects on productivity and morale. Compared to company employees, the higher numbers of reported eye, skin, and upper and lower respiratory irritation by contractor employees could be related to pharmaceutical dust exposures. Some health conditions reported by contractor employees, such as hives and asthma, are consistent with an allergic response to certain present APIs. Prompt medical attention is needed to sort out workrelatedness when these conditions occur, and a good medical surveillance program can ensure early identification and needed action. Our air sampling results indicate that employees cleaning or repairing Baker machine cells, refilling Baker machine canisters, cleaning automated counters with canned air, and hand-filling hazardous drug prescriptions may be exposed to airborne dust from uncoated tablets. Inhalation exposures to APIs were mostly below manufacturers' OELs (if an OEL was available). However, some employees were exposed to multiple APIs, the effects of which are not well understood. The surface sampling results and our observations also indicate the potential for personal clothing contamination with APIs and take home exposure. 


\section{Recommendations}

We encourage the pharmacy to use an employer-employee health and safety committee or working group to discuss the recommendations in this report and develop an action plan. These recommendations are based on the hierarchy of controls approach that groups actions by their likely effectiveness in reducing or removing hazards.

An important first step in the management of occupational exposures to pharmaceuticals is obtaining information on the potential for workplace exposures to APIs and risk of those exposures. We gathered some of this information during our evaluation. However, additional information should be gathered now and in the future, especially as new pharmaceuticals and formulations enter the market and are brought into the pharmacy. We recommend determining which pharmaceuticals are more friable and capable of producing dust. Employees who work with the pharmaceuticals may be able to help identify these dusty pharmaceuticals. We also recommend obtaining safety data sheets and reviewing manufacturer exposure guidelines and toxicity data for all tablets. Safety data sheets from the original manufacturer of the name-brand pharmaceutical or from U.S. Pharmacopeia may contain the most detailed information. This information can then be used to develop a priority list of dusty pharmaceuticals that are potentially hazardous at low concentrations (e.g., manufacturers' OELs $<10 \mu \mathrm{g} / \mathrm{m}^{3}$ or on the NIOSH list of hazardous drugs). Employees who handle these pharmaceuticals in ways that could cause the dust to become airborne may require a higher level of protection than other employees.

\section{Elimination and Substitution}

Eliminating or substituting hazardous processes or materials reduces hazards and protects employees more effectively than other approaches. Prevention through design, considering elimination or substitution when designing or developing a project, reduces the need for additional controls in the future.

1. Substitute uncoated tablets with coated tablets when that option is available. Coated tablets are less likely to produce dust.

\section{Engineering Controls}

Engineering controls reduce employees' exposures by removing the hazard from the process or by placing a barrier between the hazard and the employee. Engineering controls protect employees effectively without placing primary responsibility of implementation on the employee.

1. Install one or two partially enclosed local exhaust hoods that are ducted outdoors. The American Conference of Governmental Industrial Hygienists Industrial Ventilation Manual provides guidelines on the optimal duct and face velocity for the control of very fine light dusts [ACGIH 2010]. If two hoods are installed, one could be used for hand filling hazardous drug prescriptions in a dedicated area, and the other could be used for filling prescriptions or refilling canisters with pharmaceuticals on the priority 
list or when cleaning cells that housed pharmaceuticals on the priority list. Make sure the hoods are large enough to accommodate the tasks that will be done inside the hoods. Ducting the hoods outdoors, ideally 30 feet or more from the building's air intakes, should prevent the re-entrainment of APIs into the work environment [ASHRAE 2010]. Alternatively, a local exhaust hood with recirculated HEPA filtration could be used for work involving nonvolatile pharmaceuticals provided the manufacturers of the pharmaceuticals permit this.

2. Install seats at workstations that currently require prolonged periods of standing. Doing so will give employees an opportunity to take pressure off their feet periodically throughout the day.

3. Install adjustable workstations that can accommodate up to $90 \%$ of employees. You may want to consult with an ergonomist. Ergonomics programs have been shown to be cost effective, and ergonomic improvements may result in increased productivity and higher product quality. Promoting employee involvement in these efforts can enhance job satisfaction and increases problem-solving capabilities [NIOSH 1997b].

\section{Administrative Controls}

The term "administrative controls" refers to employer-dictated work practices and policies to reduce or prevent hazardous exposures. Their effectiveness depends on employer commitment and employee acceptance. Regular monitoring and reinforcement are necessary to ensure that policies and procedures are followed consistently.

1. Create a formal procedure for employees to report and receive feedback regarding health and safety concerns, perhaps through formation of a health and safety committee. This would involve documenting the concerns, explaining what will be done to address the concerns, or explaining why no action is necessary. The documentation of this process can then be shared with all employees. Increasing employee involvement in identifying and mitigating safety policies and procedures may benefit the company if employees feel that their concerns and suggestions are heard and appreciated.

2. Create a mechanism whereby all employees have the opportunity to make anonymous reports of health and safety concerns.

3. Discontinue the point system for contractor employees' illness absences. Point systems can discourage reporting of illness and encourage workers to report to work when they are ill. When workers report to work with a contagious illness, they put their coworkers at increased risk of becoming ill.

4. Explore further why some contractor employees reported a strained interpersonal relationship with their supervisor. An anonymous survey focusing on this topic may be helpful. A survey can be done by an external consultant, who can also hold confidential interviews or focus groups with employees about employer-employee relations. The Society for Industrial and Organizational Psychology maintains a consultant locator at http://www.siop.org/consultantlocator/search.aspx. The American Society of Safety 
Engineers also maintains directories of qualified consultants at http://www.asse.org/ practicespecialties/consultants/.

5. Encourage all employees to report possible work-related health conditions early. Employees with persistent symptoms should be evaluated by an occupational medicine physician or a medical provider specializing in workplace diseases and illnesses.

6. Under the guidance of an occupational medicine physician, employees who experience signs and symptoms of allergy to specific pharmaceuticals should be moved to a new work area. Wages and benefits should be maintained as per the original position.

7. Update the standard operating procedures and training on the safe handling of pharmaceuticals (including hazardous drugs) to include the control measures that you implement from our recommendations. For example, procedures and annual training on how to properly use and maintain engineering controls (e.g., local exhaust hood) and personal protective equipment may need updating.

8. Consult a ventilation specialist to install and commission the local exhaust hood(s). Validate hood performance at least annually.

9. Ask the company industrial hygienist to evaluate potential exposures to pharmaceutical dust when employees replace the HEPA filter in the local exhaust hood if the decision is made to continue using a recirculating hood. The purpose of this evaluation would be to verify whether the current standard operating procedure protects employees from being exposed to a mixture of pharmaceuticals.

10. Follow the manufacturer's guidelines when replacing the HEPA filter in the vacuum. Wear nitrile gloves and work under a hood when doing this task.

\section{Personal Protective Equipment}

Personal protective equipment is the least effective means for controlling hazardous exposures. Proper use of personal protective equipment requires a comprehensive program and a high level of employee involvement and commitment. The right personal protective equipment must be chosen for each hazard. Supporting programs such as training, changeout schedules, and medical assessment may be needed. Personal protective equipment should not be the sole method for controlling hazardous exposures. Rather, personal protective equipment should be used until effective engineering and administrative controls are in place.

1. Require employees to wear nitrile gloves instead of vinyl gloves when dermal exposure to pharmaceutical dust is possible, including when unpacking shipments of hazardous drugs or handling prescription bottles filled with hazardous drugs. Nitrile gloves are more resistant to isopropyl alcohol and many other chemicals than vinyl gloves.

2. Replace neoprene gloves in the existing hazardous drug spill kits with chemotherapy gloves approved by the U.S. Food and Drug Administration. These gloves provide protection against liquid chemotherapy drugs. 
3. Provide a sufficient number of respirator models and sizes from which employees can choose a respirator for voluntary use. Train employees on how to select the appropriate size N95 filtering facepiece respirator and how to adjust these respirators to seal around their face. Notify all employees of the location(s) where these respirators are located.

4. Provide safety glasses and long-sleeve protective clothing to employees who perform tasks outside the hood that could generate airborne pharmaceutical dust or hand fill hazardous drug prescriptions even when filling them inside the local exhaust hood. The protective clothing should either be disposable or kept at work and laundered weekly by a laundry service. Wearing protective clothing should minimize the potential for take-home exposure. 


\section{Appendix A: Analytical Methods}

Gravimetric analysis of the personal and area inhalable dust air samples was performed using NIOSH Method 0600 [NIOSH 2012]. After gravimetric analysis, the air samples were further analyzed for lactose and/or specific APIs. The surface wipe samples were also analyzed for lactose or specific APIs. Of these APIs, warfarin was analyzed using NIOSH Method 5002 [NIOSH 2012]. All other APIs and lactose were analyzed using BVNA methods. These methods are briefly summarized below for each analyte.

\section{Lactose}

Air samples were extracted in 2 milliliters $(\mathrm{mL})$ of deionized water. The wipe samples were extracted in $10 \mathrm{~mL}$ of deionized water. After sonicating for 15 minutes, the samples were allowed to stand for 15 minutes before being transferred to autosampler vials. The extracted samples (air and wipe) were analyzed by high performance liquid chromatography using the parameters below.

Instrument: Dionex 3000

Column: Dionex CarboPac PA1, $4 \mathrm{~mm} \times 250 \mathrm{~mm}$

Column flow rate: $1 \mathrm{~mL}$ per minute

Column temperature: Ambient

Injection volume: 200 microliters

Detector: Electrochemical detector

Mobile phase: Isocratic, 200 millimolar (mM) sodium hydroxide in deionized water

\section{Lisinopril and Hydrochlorothiazide}

Air samples were processed as described for lactose analysis and analyzed by high performance liquid chromatography using the parameters below.

Instrument: Agilent 1100

Column: Waters Spherisorb C8, $150 \mathrm{~mm} \times 4.6 \mathrm{~mm}, 5 \mu \mathrm{m}$ particle size

Column flow rate: $1 \mathrm{~mL}$ per minute

Column temperature: $40^{\circ} \mathrm{C}$

Injection volume: 30 microliters

Detector: Ultraviolet/visible

Wavelength: 215 nanometer

Mobile phase: Isocratic $85 \%$ (Dipotassium phosphate, $0.1 \%$ phosphoric acid) $/ 15 \%$ methanol

\section{Hydrochlorothiazide and Triamterene}

Air samples were transferred into an extraction vessel. Then, $2 \mathrm{~mL}$ of $90 \% 5 \mathrm{mM}$ monopotassium phosphate in deionized water $(\mathrm{pH}=4$ with monopotassium phosphate) $/ 10 \%$ acetonitrile solution was rinsed through the cowl and added to each sample. After sonicating for 15 minutes, the samples were allowed to stand for 15 minutes before being transferred to autosampler vials for analysis by high performance liquid chromatography using the parameters below. 
Instrument: Agilent 1100

Column: Waters Spherisorb C8, $150 \mathrm{~mm} \times 4.6 \mathrm{~mm}, 5 \mu \mathrm{m}$ particle size

Column flow rate: 1.0 milliliters per minute $(\mathrm{mL} / \mathrm{min})$

Column temperature: $40^{\circ} \mathrm{C}$

Injection volume: 50 microliters

Detector: Ultraviolet/visible

Wavelength: 271 nanometer

Mobile phase: Isocratic $90 \% 5 \mathrm{mM}$ monopotassium phosphate in deionized water $\left(\mathrm{pH}=4\right.$ with $\left.\mathrm{H}_{3} \mathrm{PO}_{4}\right), 10 \%$ acetonitrile

\section{Hydrocodone}

Air samples were extracted in $2 \mathrm{~mL}$ of a $50 \%$ (15 mM sodium lauryl sulfate, $15 \mathrm{mM}$ dipotassium phosphate, $0.1 \%$ phosphoric acid) $/ 5 \%$ acetonitrile $/ 45 \%$ methanol solution. Wipe samples were extracted in $10 \mathrm{~mL}$ of the same extraction solvent. After sonicating for 15 minutes, the samples were transferred to autosampler vials. The extracted samples (air and wipe) were analyzed by liquid chromatography/mass spectrometry using the parameters below.

Instrument: Agilent 1100

Column: MacMod Halo C18, $4.6 \mathrm{~mm} \times 75 \mathrm{~mm}, 2.7 \mu \mathrm{m}$ particle size

Column flow rate: $1.5 \mathrm{~mL}$ per minute

Column temperature: $40^{\circ} \mathrm{C}$

Injection volume: 50 microliters

Detector: Ultraviolet/visible

Wavelength: 210 nanometer

Mobile phase: Isocratic 50\% $15 \mathrm{mM}$ sodium lauryl sulfate, $15 \mathrm{mM}$ dipotassium phosphate, $0.1 \%$ phosphoric acid, $5 \%$ acetonitrile

\section{Methotrexate}

Air samples were extracted in $1 \mathrm{~mL}$ of a $25 \% 10 \mathrm{mM}$ ammonium acetate $(0.1 \%$ formic acid) $/ 75 \%$ acetonitrile $(0.1 \%$ formic acid $)$ solution. After shaking the samples for 30 minutes, the samples were transferred to autosampler vials. All calibration points, quality control spikes, and samples were then spiked with 10 microliter concentrated internal standard (200 nanograms per $\mathrm{mL}$ methotrexate-D3). Wipe samples were extracted in 10 $\mathrm{mL}$ of a 2 nanograms per $\mathrm{mL}$ methotrexate-D3 in 25\% $10 \mathrm{mM}$ ammonium acetate $(0.1 \%$ formic acid) $/ 75 \%$ acetonitrile $(0.1 \%$ formic acid) solution. After sonicating for 15 minutes, the samples were allowed to stand for 15 minutes before being transferred to autosampler vials. The extracted samples (air and wipe) were analyzed by liquid chromatography/mass spectrometry using the parameters below.

Instrument: Agilent 1200

Column: Atlantis Hilic Silica, $4.6 \mathrm{~mm} \times 100 \mathrm{~mm}, 3$ um particle size

Column flow rate: $1.0 \mathrm{~mL}$ per minute

Column temperature: $30^{\circ} \mathrm{C}$

Injection volume: 10 microliters

Detector: API 4000 Turbo V source with electro-spray ionization probe 
Ions used: 455.2/308.2; Internal Standard 458.3/311.2

Mobile phase: Isocratic $25 \% 10 \mathrm{mM}$ ammonium acetate $(0.1 \%$ formic acid $), 75 \%$ acetonitrile $(0.1 \%$ formic acid $)$

\section{Methocarbamol}

Air samples were extracted in $2 \mathrm{~mL}$ of a $60 \% 20 \mathrm{mM}$ monopotassium phosphate $(\mathrm{pH}=3$ with phosphoric acid) in deionized water $/ 40 \%$ methanol solution was added to each sample. Wipe samples were extracted in $10 \mathrm{~mL}$ of a $90 \%$ (15 mM heptane sulfonic acid $/ 10 \mathrm{mM}$ dipotassium phosphate $/ 0.1 \%$ phosphoric acid) $/ 10 \%$ acetonitrile solution. After sonicating for 15 minutes, the samples were allowed to stand for 15 minutes before being transferred to autosampler vials. The extracted samples (air and wipe) were analyzed by high performance liquid chromatography using the parameters below.

Instrument: Agilent 1100

Column: Waters Symmetry C18, $4.6 \mathrm{~mm} \times 150 \mathrm{~mm}, 5 \mathrm{um}$ particle size

Column flow rate: $1.0 \mathrm{~mL} / \mathrm{min}$

Column temperature: $25^{\circ} \mathrm{C}$

Injection volume: 50 microliters

Detector: Ultraviolet/visible

Detection wavelength: 275 nanometer

Mobile phase: Isocratic 60\% $20 \mathrm{mM}$ monopotassium phosphate $(\mathrm{pH}=3$ with phosphoric acid) in deionized water, $40 \%$ methanol

\section{Buspirone}

Air samples were transferred into an extraction vessel. Then, $2 \mathrm{~mL}$ of a $70 \% 10 \mathrm{mM}$ monopotassium phosphate in deionized water $/ 30 \%$ acetonitrile solution was rinsed through the cowl and added to each sample. After sonicating for 15 minutes, the samples were allowed to stand for 15 minutes before being transferred to autosampler vials for analysis by high performance liquid chromatography using the parameters below.

Instrument: Agilent 1100

Column: Waters Xterra RP18, $4.6 \mathrm{~mm} \times 150 \mathrm{~mm}, 3.5 \mu \mathrm{m}$ particle size

Column flow rate: $1.5 \mathrm{~mL} / \mathrm{min}$

Column temperature: $30^{\circ} \mathrm{C}$

Injection volume: 25 microliters

Detector: Ultraviolet/visible

Detection wavelength: 238 nanometer

Mobile phase: Isocratic 70\% $10 \mathrm{mM}$ monopotassium phosphate in deionized water, $30 \%$ acetonitrile

\section{Gabapentin}

Air samples were transferred into an extraction vessel. Then, $2 \mathrm{~mL}$ of a $10 \mathrm{mM}$ sodium borate decahydrate solution was rinsed through the cowl and added to each sample. After sonicating for 15 minutes, the samples were allowed to stand for 15 minutes. Finally, 100 microliters of each sample, quality control spike, and calibration standard was transferred to 
autosampler vials and spiked with 15 microliters of derivatizing agent (Vial 2B added to Vial 2A of Accq-flour Reagent Kit from Waters Lot \#689882215), mixed, and analyzed by high performance liquid chromatography using the parameters below.

Instrument: Agilent 1100

Column: Zorbax SB C18, $4.6 \mathrm{~mm} \times 250 \mathrm{~mm}, 5 \mu \mathrm{m}$ particle size

Column flow rate: $1.0 \mathrm{~mL} / \mathrm{min}$

Column temperature: $35^{\circ} \mathrm{C}$

Injection volume: 10 microliters

Detector: Waters 474 fluorescence detector

Excitation: 245

Emission: 480

Mobile phase: Isocratic 70\% (1\% triethylamine, $0.75 \% \mathrm{H}_{3} \mathrm{PO}_{4}$ in deionized water), $30 \%$ acetonitrile

\section{Captopril}

Air samples were extracted in $2 \mathrm{~mL}$ of a $55 \%$ methanol $/ 45 \%$ deionized water $/ 0.05 \%$ phosphoric acid solution. After sonicating for 10 minutes, the samples were allowed to stand for 20 minutes before being transferred to autosampler vials for analysis by high performance liquid chromatography using the parameters below.

Instrument: Agilent 1100

Column: Zorbax XDB C18, $4.6 \mathrm{~mm} \times 250 \mathrm{~mm}, 5 \mu \mathrm{m}$ particle size

Column flow rate: $1.0 \mathrm{~mL} / \mathrm{min}$

Column temperature: $40^{\circ} \mathrm{C}$

Injection volume: 50 microliters

Detector: Ultraviolet/visible

Detection wavelength: 220 nanometer

Mobile Phase: Isocratic 55\% methanol $/ 45 \%$ deionized water $/ 0.05 \%$ phosphoric acid solution

\section{Naproxen}

Air samples were transferred into an extraction vessel. Then, $2 \mathrm{~mL}$ of a $54 \%$ deionized water $/ 5 \%$ acetonitrile $/ 1 \%$ glacial acetic acid solution was rinsed through the cowl and added to each sample. After sonicating for 15 minutes, the samples were allowed to stand for 15 minutes before being transferred to autosampler vials for analysis by high performance liquid chromatography using the parameters below.

Instrument: Agilent 1100

Column: MacMod Halo C18, $4.6 \mathrm{~mm} \times 75 \mathrm{~mm}, 2.7 \mu \mathrm{m}$ particle size

Column flow rate: $1.0 \mathrm{~mL} / \mathrm{min}$

Column temperature: $40^{\circ} \mathrm{C}$

Injection volume: 40 microliters

Detector: Ultraviolet/visible

Detection wavelength: 238 nanometer

Mobile phase: Isocratic 54\% deionized water $/ 45 \%$ acetonitrile $/ 1 \%$ glacial acetic acid 


\section{Furosemide}

Air samples were transferred into an extraction vessel. Then, $1 \mathrm{~mL}$ of a $60 \%$ (2\% acetic acid in deionized water) $/ 40 \%$ acetonitrile solution was rinsed through the cowl and added to each sample. After sonicating for 15 minutes, the samples were allowed to stand for 15 minutes before being transferred to autosampler vials for analysis by high performance liquid chromatography using the parameters below.

Instrument: Agilent 1100

Column: Waters Xterra RP18, $4.6 \mathrm{~mm} \times 150 \mathrm{~mm}, 3.5 \mu \mathrm{m}$ particle size

Column flow rate: $1.0 \mathrm{~mL} / \mathrm{min}$

Column temperature: $40^{\circ} \mathrm{C}$

Injection volume: 25 microliters

Detector: Ultraviolet/visible

Detection wavelength: 340 nanometer

Mobile phase: Isocratic 60\% (2\% acetic acid in deionized water), 40\% acetonitrile

\section{Levothyroxine}

Air samples were desorbed in 20 nanograms per $\mathrm{mL}$ thyroxine in $30 \%$ deionized water $(0.1 \%$ formic acid) $/ 70 \%$ acetonitrile solution. After sonicating for 15 minutes, the samples were transferred to autosampler vials for analysis by liquid chromatography/tandem mass spectrometry using the parameters below.

Instrument: Agilent 1100

Column: Atlantis Hilic Silica, $50 \mathrm{~mm} \times 2.1 \mathrm{~mm}, 3 \mu \mathrm{m}$ pore size

Column flow rate: $0.3 \mathrm{~mL}$ per minute

Column temperature: $35^{\circ} \mathrm{C}$

Injection volume: 20 microliters

Detector: AB Sciex API $3000 \mathrm{MS} / \mathrm{MS}$ with turbo ion spry source

Source temperature: $350^{\circ} \mathrm{C}$

MS function: Multiple reaction monitoring

Levothyroxine quantitation transition: $777.8-731.8$ atomic mass units

Thyroxine (internal standard) transition: $783.78-737.65$ atomic mass units

Mobile phase: Isocratic $30 \%$ deionized water $(0.1 \%$ formic acid $) / 70 \%$ acetonitrile

$(0.1 \%$ formic acid $)$

\section{Glipizide}

Wipe samples were extracted in $10 \mathrm{~mL}$ of a $50 \% 20 \mathrm{mM}$ dipotassium phosphate $/ 50 \%$

methanol solution. After sonicating for 15 minutes, the samples were allowed to stand for 15 minutes before being transferred to auto-sampler vials for analysis by high performance liquid chromatography using the parameters below.

Instrument: Agilent 1100

Column: Waters Xterra RP-18, $4.6 \mathrm{~mm} \times 150 \mathrm{~mm}, 3.5 \mu \mathrm{m}$ particle size

Column flow rate: $0.75 \mathrm{~mL} / \mathrm{min}$

Column temperature: $40^{\circ} \mathrm{C}$

Injection volume: 75 microliters 
Detector: Ultraviolet/visible

Detection wavelength: 275 nanometer

Mobile phase: Gradient (linear)

Mobile phase A: $10 \mathrm{mM}$ dipotassium phosphate (pH 3 using phosphoric acid)

Mobile phase B: Methanol 


\section{Appendix B: Real-Time Particle Measurements}

Real-time particle sampling was mostly done near the breathing zones of employees who also wore personal air samplers. Personal air sample numbers are provided in some of the figures below for cross-referencing with sample results in Table 13.

\section{Baker Refill}

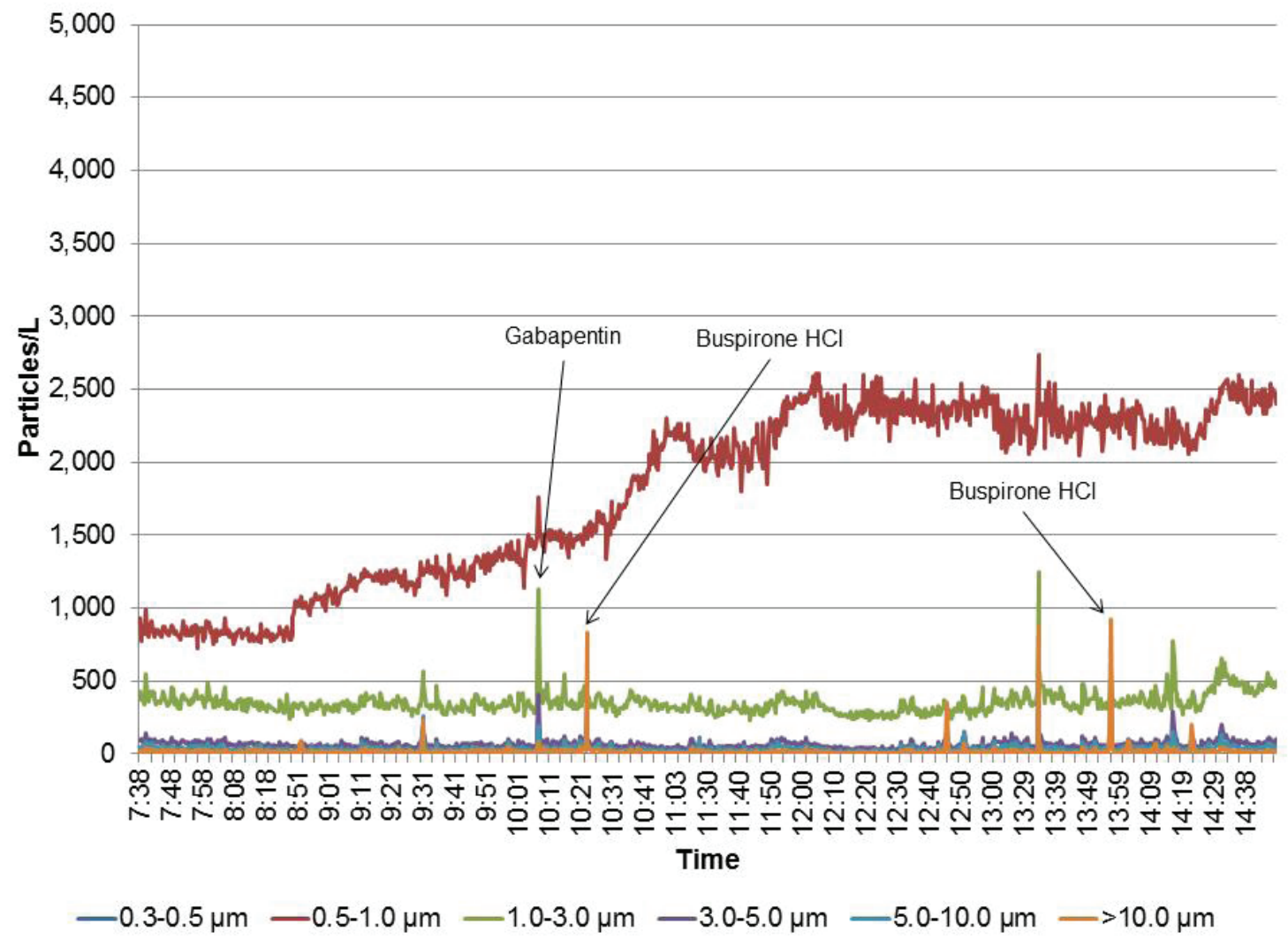

Figure B1. Real-time particle number concentrations measured near the breathing zone of an employee who refilled the Baker machine during first shift of day 1 (side-by-side sample nos. 13 and 17). The APIs that were handled during refill are noted above the peaks in particle concentrations that occurred at the same time. Number concentrations for particles $0.3-0.5 \mu \mathrm{m}$ in diameter $(20,000-40,000$ particles per liter [particles/L]) exceeded the upper range of this graph. 


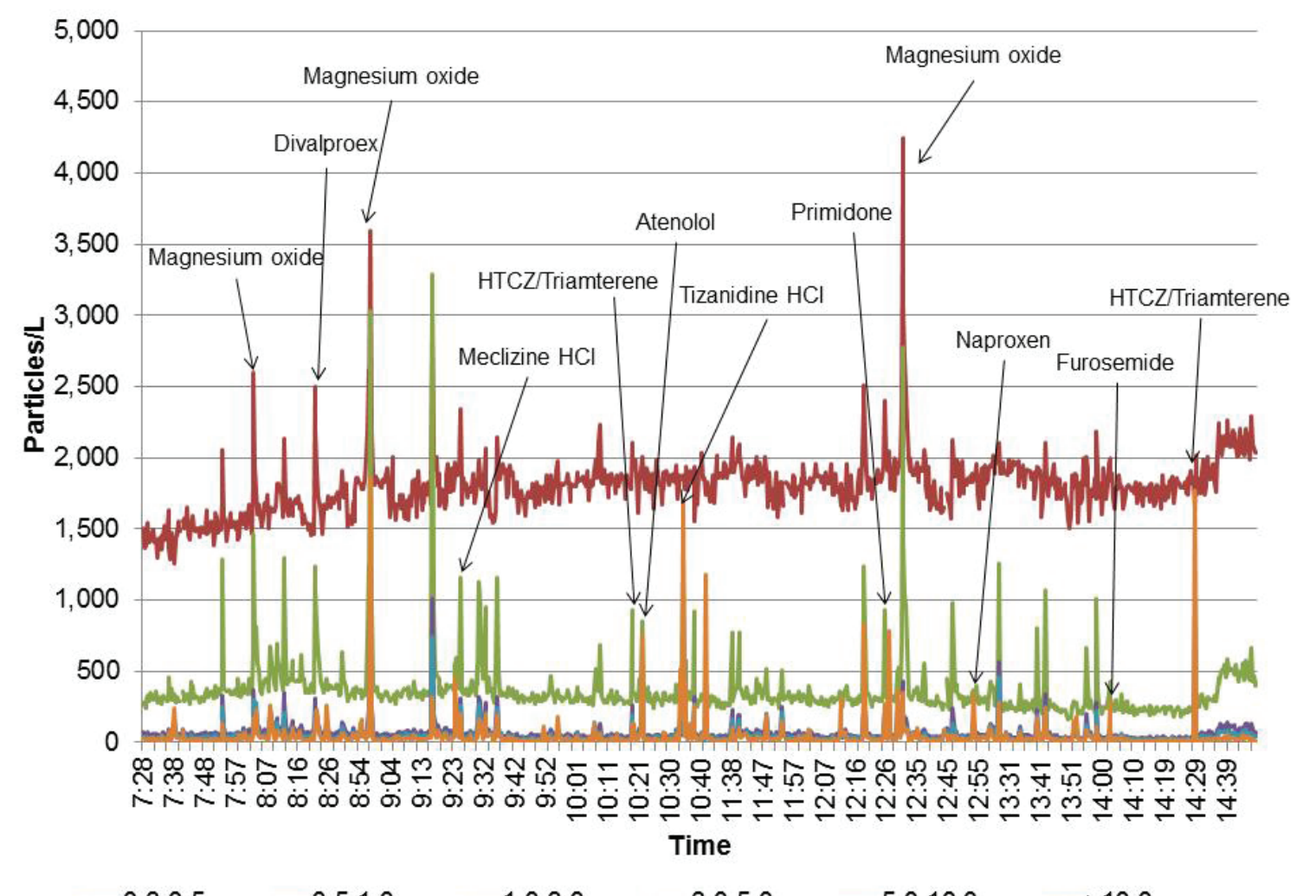

Figure B2. Real-time particle number concentrations measured near the breathing zone of an employee who refilled the Baker machine during first shift of day 2 (side-by-side sample nos. 25 and 40). The APIs that were handled during refill are noted above the peaks in particle concentrations that occurred at the same time. Number concentrations for particles $0.3-0.5 \mu \mathrm{m}$ in diameter $(30,000-40,000$ particles/L) exceeded the upper range of this graph. 


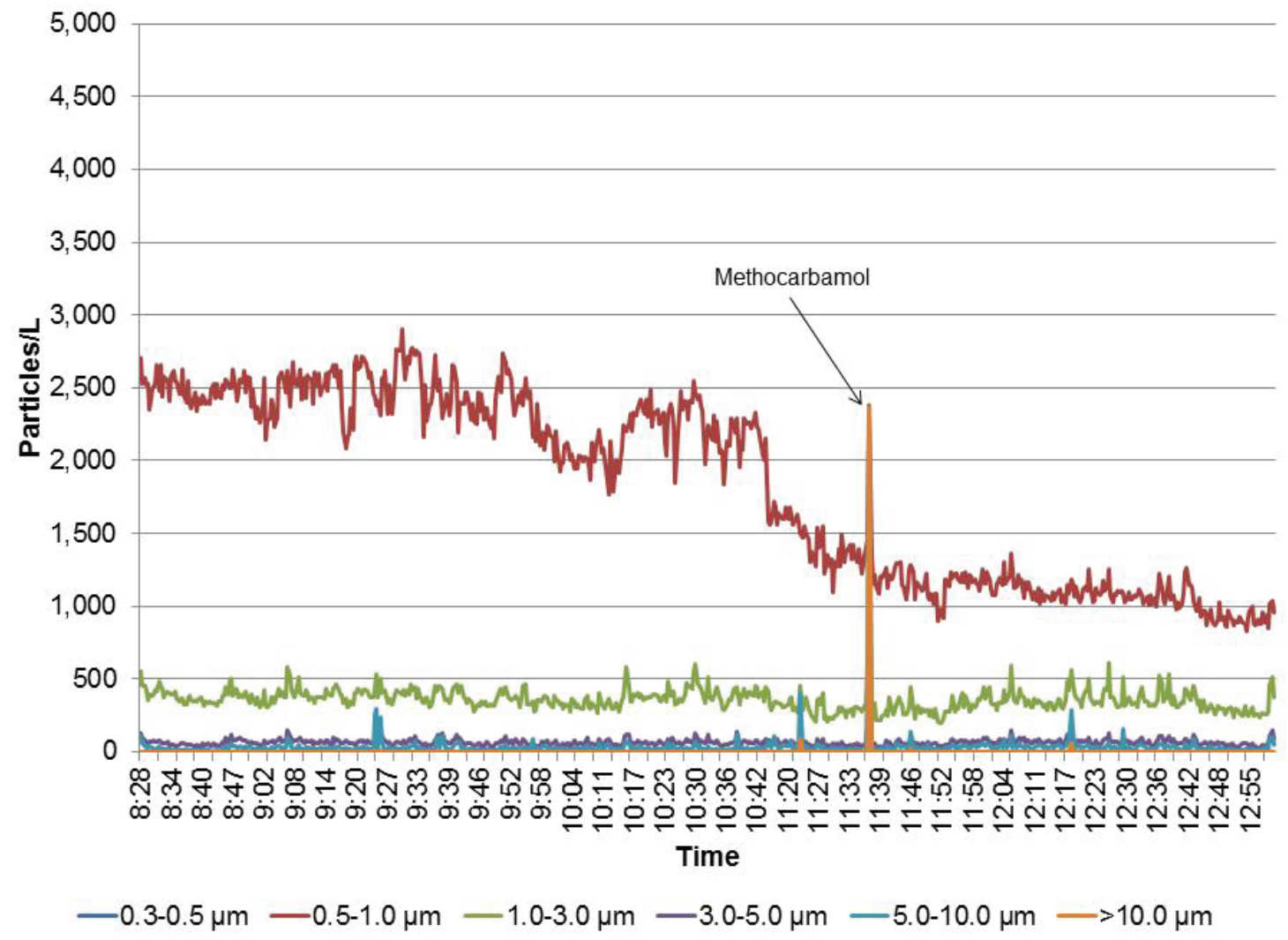

Figure B3. Real-time particle number concentrations measured near the breathing zone of an employee who refilled the Baker machine during first shift of day 3. The APIs that were handled during refill are noted above the peaks in particle concentrations that occurred at the same time. Number concentrations for particles $0.3-0.5 \mu \mathrm{m}$ in diameter $(15,000-35,000$ particles/L) exceeded the upper range of this graph. 


\section{Baker Maintenance}

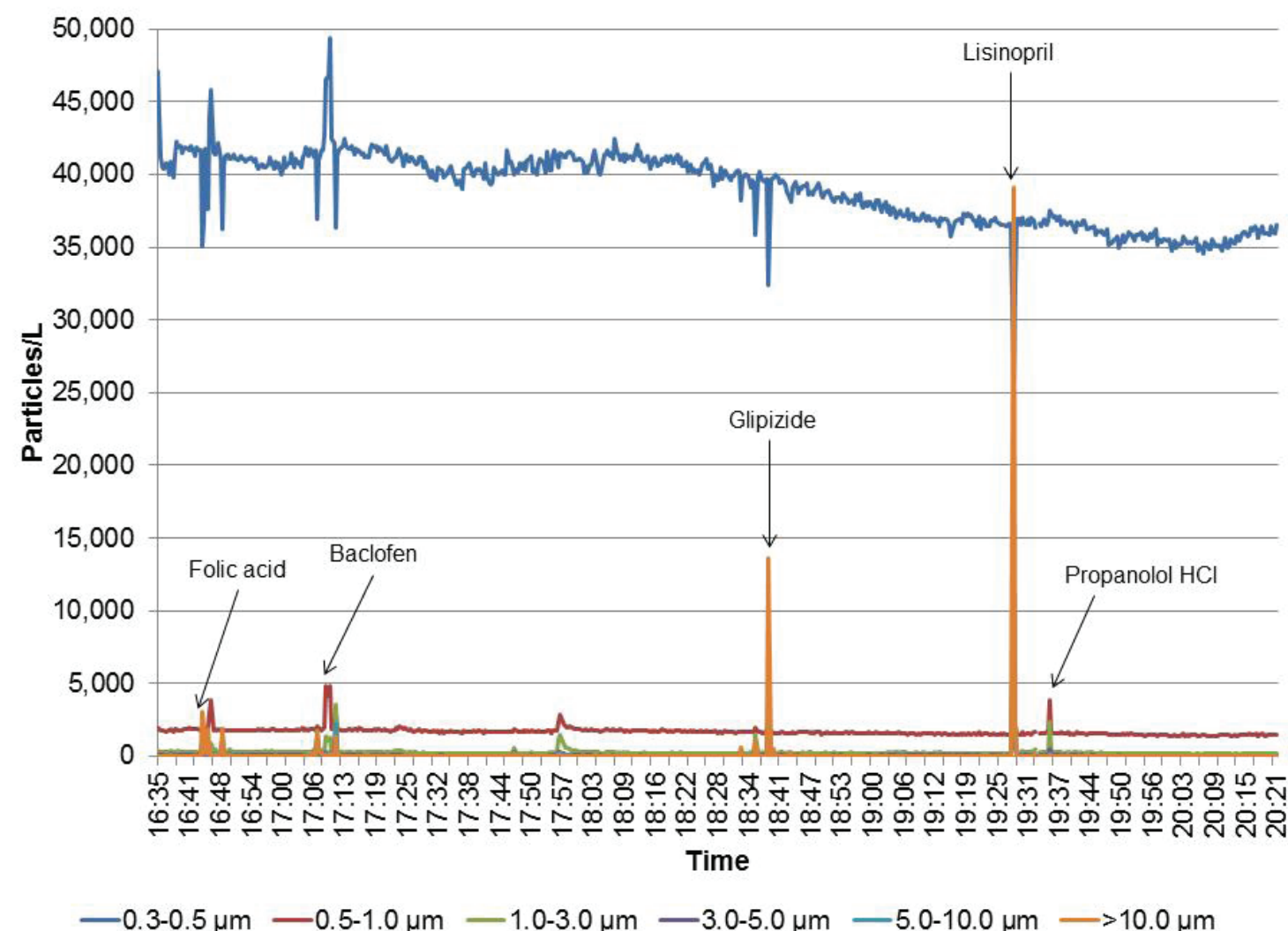

Figure B4. Real-time particle number concentrations measured near the breathing zone of an employee who maintained the Baker machine during second shift of day 2 (sample no. 21). The APIs that were housed in cells that were cleaned or repaired are noted above the peaks in particle concentrations that occurred at the same time. 


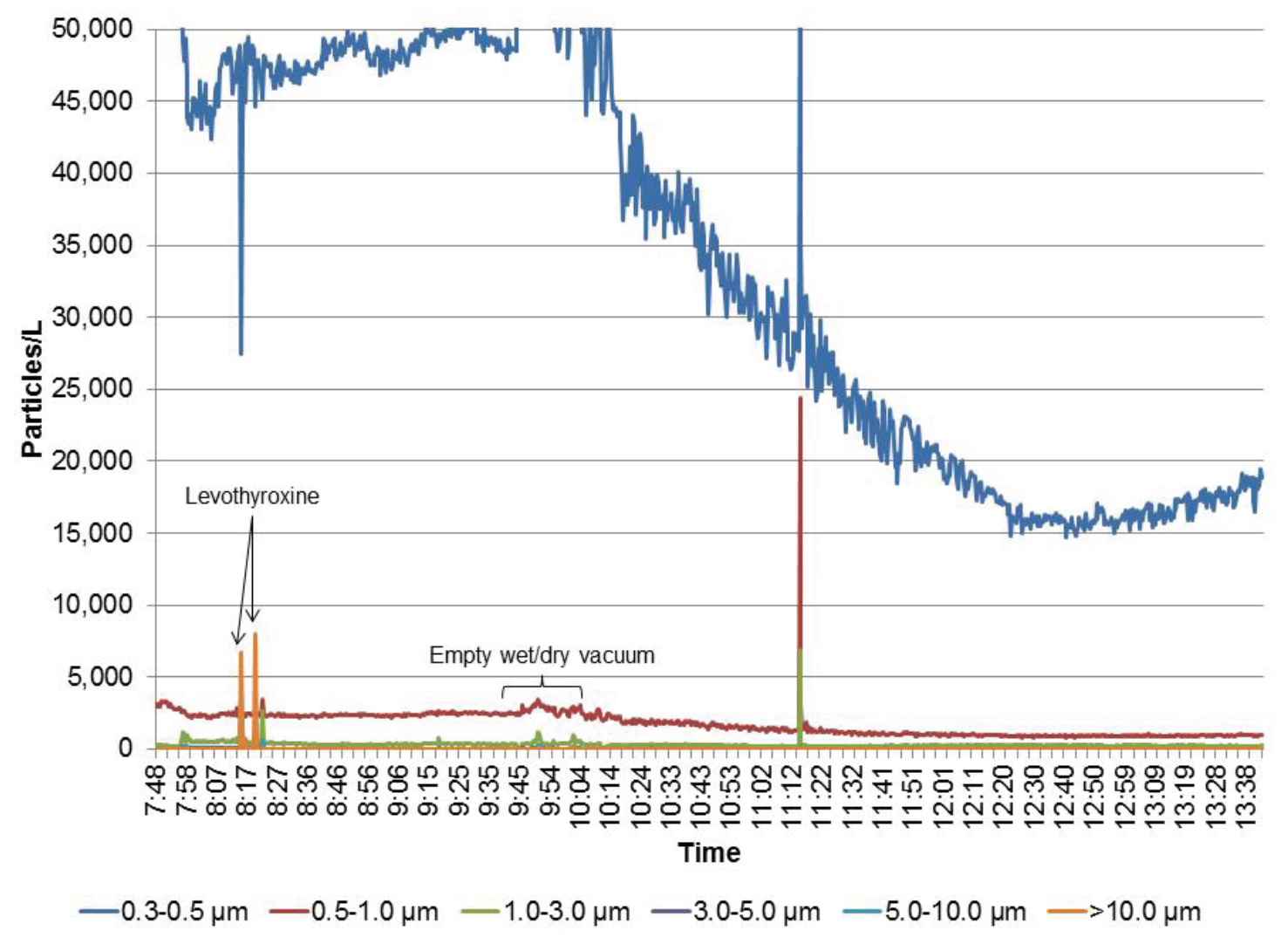

Figure B5. Real-time particle number concentrations measured near the breathing zone of an employee who maintained the Baker machine during first shift of day 3. The APIs that were housed in cells that were cleaned or repaired are noted above the peaks in particle concentrations that occurred at the same time. For a brief period ( 20 minutes), we also did real-time air sampling near the personal breathing zone of the housekeeping employee who emptied the wet/dry vacuum. 


\section{Manual Count}

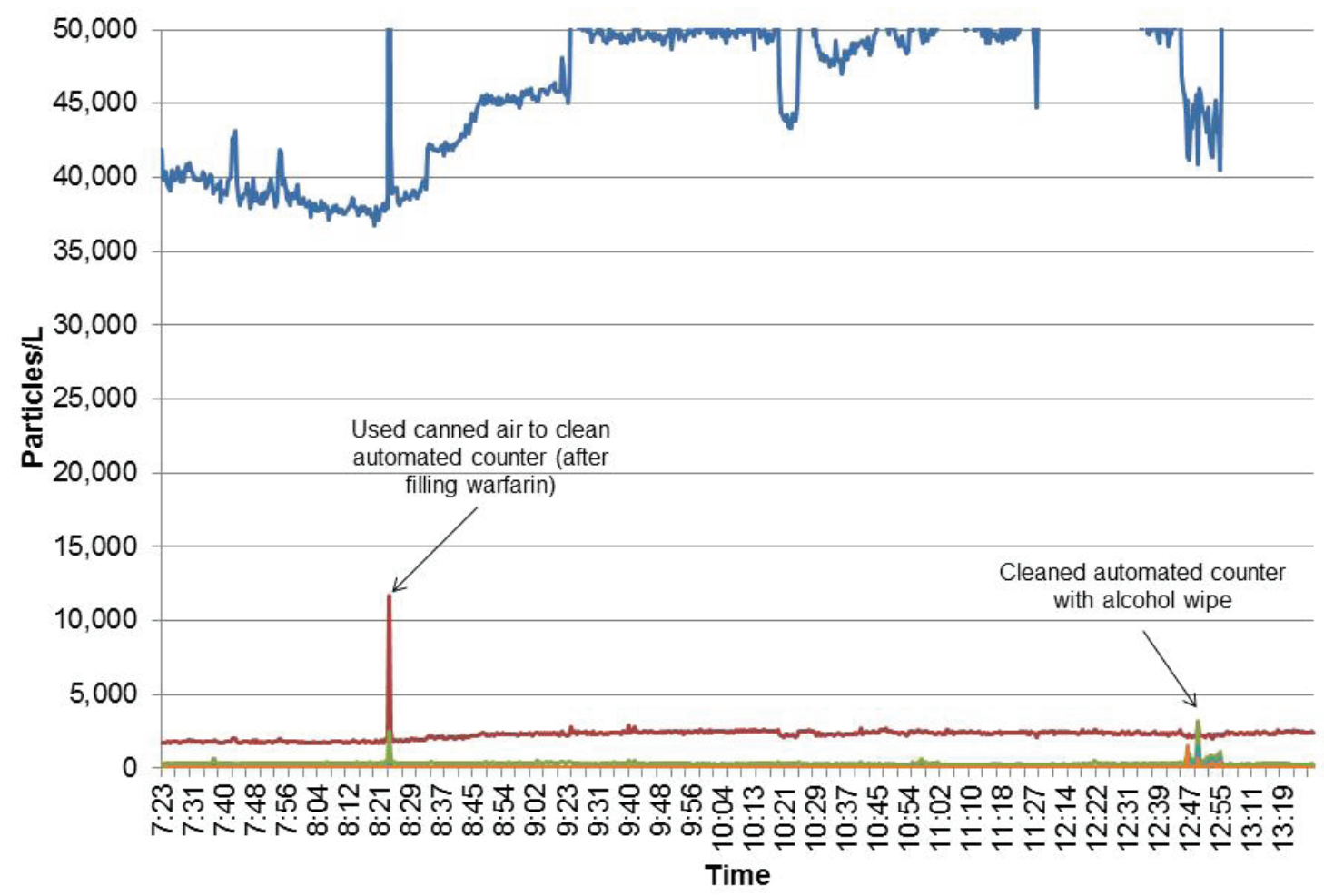

$-0.3-0.5 \mu \mathrm{m}-0.5-1.0 \mu \mathrm{m}-1.0-3.0 \mu \mathrm{m}-3.0-5.0 \mu \mathrm{m}-5.0-10.0 \mu \mathrm{m} \longrightarrow 10.0 \mu \mathrm{m}$

Figure B6. Real-time particle number concentrations measured near the breathing zone of an employee who manually filled prescriptions during first shift of day 2. Specific tasks are noted above the particle concentrations that occurred at the same time. 


\section{Hazardous Drugs}

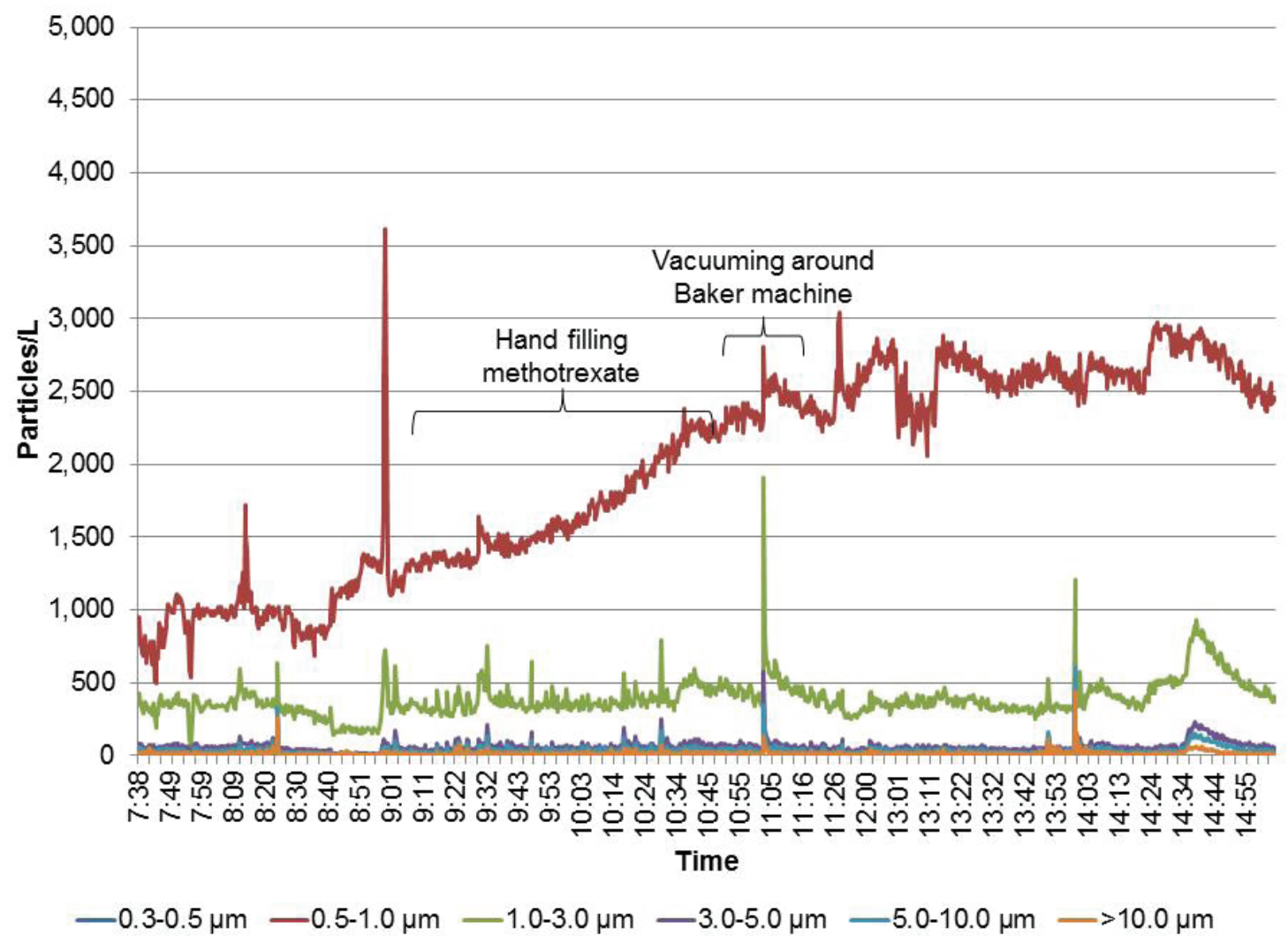

Figure B7. Real-time particle number concentrations measured near the breathing zone of an employee who hand-filled bulk and hazardous drug prescriptions (i.e., methotrexate) during first shift of day 1 . For a brief period ( 20 minutes), we also did real-time air sampling near the personal breathing zone of the housekeeping employee who vacuumed around the Baker machine. Number concentrations for particles $0.3-0.5 \mu \mathrm{m}$ in diameter (20,000-45,000 particles/L) exceeded the upper range of this graph. 


\section{Appendix C: Minimum Detectable and Quantifiable Concentrations}

Table C1. MDCs and MQCs for inhalable dust, lactose, and APIs sampled in air*

\begin{tabular}{lcc}
\hline Analyte & MDC $\left(\mu \mathrm{g} / \mathrm{m}^{3}\right)$ & $\mathrm{MQC}\left(\mu \mathrm{g} / \mathrm{m}^{3}\right)$ \\
\hline Inhalable dust & 100 & 470 \\
Lactose & 0.003 & 0.0091 \\
Warfarin & 0.7 & 2.1 \\
Methotrexate & 0.0001 & 0.00035 \\
HCTZ & 0.02 & 0.065 \\
Triamterene & 0.02 & 0.065 \\
Lisinopril & 0.1 & 0.36 \\
Buspirone & 5 & 18 \\
Captopril & 0.09 & 0.28 \\
Furosemide & 0.05 & 0.18 \\
Gabapentin & 0.05 & 0.18 \\
Hydrocodone & 0.01 & 0.043 \\
Methocarbamol & 0.05 & 0.18 \\
Naproxen & 0.0001 & 0.00036 \\
Levothyroxine & 0.0003 & 0.00092 \\
\hline
\end{tabular}

${ }^{*}$ Based on the average volume of air ( 0.92 cubic meters) collected during full-shift sampling (approximately 8 hours). 


\section{Appendix D: Occupational Exposure Limits and Health Effects}

NIOSH investigators refer to mandatory (legally enforceable) and recommended OELs for chemical, physical, and biological agents when evaluating workplace hazards. OELs have been developed by federal agencies and safety and health organizations to prevent adverse health effects from workplace exposures. Generally, OELs suggest levels of exposure that most employees may be exposed to for up to 10 hours per day, 40 hours per week, for a working lifetime, without experiencing adverse health effects. However, not all employees will be protected if their exposures are maintained below these levels. Some may have adverse health effects because of individual susceptibility, a pre-existing medical condition, or a hypersensitivity (allergy). In addition, some hazardous substances act in combination with other exposures, with the general environment, or with medications or personal habits of the employee to produce adverse health effects. Most OELs address airborne exposures, but some substances can be absorbed directly through the skin and mucous membranes.

Most OELs are expressed as a time-weighted average exposure. A time-weighted average refers to the average exposure during a normal 8- to 10-hour workday. Some chemical substances and physical agents have recommended short-term exposure limit or ceiling values. Unless otherwise noted, the short-term exposure limit is a 15-minute time-weighted average exposure. It should not be exceeded at any time during a workday. The ceiling limit should not be exceeded at any time.

In the United States, OELs have been established by federal agencies, professional organizations, state and local governments, and other entities. Some OELs are legally enforceable limits; others are recommendations.

- The U.S. Department of Labor OSHA permissible exposure limits (29 CFR 1910 [general industry]; 29 CFR 1926 [construction industry]; and 29 CFR 1917 [maritime industry]) are legal limits. These limits are enforceable in workplaces covered under the Occupational Safety and Health Act of 1970.

- NIOSH recommended exposure limits are recommendations based on a critical review of the scientific and technical information and the adequacy of methods to identify and control the hazard. NIOSH recommended exposure limits are published in the NIOSH Pocket Guide to Chemical Hazards [NIOSH 2010]. NIOSH also recommends risk management practices (e.g., engineering controls, safe work practices, employee education/training, personal protective equipment, and exposure and medical monitoring) to minimize the risk of exposure and adverse health effects.

- Other OELs commonly used and cited in the United States include the threshold limit values, which are recommended by the American Conference of Governmental Industrial Hygienists, a professional organization, and the workplace environmental exposure levels, which are recommended by the American Industrial Hygiene Association, another professional organization. The threshold limit values and 
workplace environmental exposure levels are developed by committee members of these associations from a review of the published, peer-reviewed literature. These OELs are not consensus standards. Threshold limit values are considered voluntary exposure guidelines for use by industrial hygienists and others trained in this discipline "to assist in the control of health hazards" [ACGIH 2013]. Workplace environmental exposure levels have been established for some chemicals "when no other legal or authoritative limits exist" [AIHA 2013].

Outside the United States, OELs have been established by various agencies and organizations and include legal and recommended limits. The Institut für Arbeitsschutz der Deutschen Gesetzlichen Unfallversicherung (Institute for Occupational Safety and Health of the German Social Accident Insurance) maintains a database of international OELs from European Union member states, Canada (Québec), Japan, Switzerland, and the United States. The database, available at http://www.dguv.de/ifa/Gefahrstoffdatenbanken/GESTIS-InternationaleGrenzwerte-für-chemische-Substanzen-limit-values-for-chemical-agents/index-2.jsp, contains international limits for more than 1,500 hazardous substances and is updated periodically.

OSHA requires an employer to furnish employees a place of employment free from recognized hazards that cause or are likely to cause death or serious physical harm [Occupational Safety and Health Act of 1970 (Public Law 91-596, sec. 5(a)(1))]. This is true in the absence of a specific OEL. It also is important to keep in mind that OELs may not reflect current health-based information.

When multiple OELs exist for a substance or agent, NIOSH investigators generally encourage employers to use the lowest OEL when making risk assessment and risk management decisions. NIOSH investigators also encourage use of the hierarchy of controls approach to eliminate or minimize workplace hazards. This includes, in order of preference, the use of (1) substitution or elimination of the hazardous agent, (2) engineering controls (e.g., local exhaust ventilation, process enclosure, dilution ventilation), (3) administrative controls (e.g., limiting time of exposure, employee training, work practice changes, medical surveillance), and (4) personal protective equipment (e.g., respiratory protection, gloves, eye protection, hearing protection).

\section{Active Pharmaceutical Ingredients}

Other than warfarin, none of the APIs measured in air have OELs established by federal agencies or national organizations. However, many of them do have OELs established by pharmaceutical companies using a control banding process. Control banding, a qualitative risk assessment and risk management tool, is a complementary approach to protecting employee health that focuses resources on exposure controls by describing how a risk needs to be managed. This approach can be applied in situations where authoritative OELs have not been established or can be used to supplement such OELs. In the pharmaceutical industry, APIs are placed into hazard categories using data such as potency, severity of acute effects, lethal dose, irritation, and sensitization [Naumann et al. 1996; Naumann 2005; Zalk and Nelson 2008]. Once placed into hazard categories, pharmaceuticals are often assigned OELs 
or hazard control bands. Pharmaceutical companies may provide these OELs or hazard control bands on their safety data sheets, along with potential acute and chronic health effects from workplace exposures. Table $\mathrm{C} 1$ provides the manufacturers' OELs or hazard control bands for the APIs measured in this evaluation. Other manufacturers may have OELs in addition to those listed in Table D1. Maintaining exposures below these manufacturers' OELs should minimize any potential health effects. However, OELs typically do not consider possible synergistic effects from multiple API exposures. More information on control banding is available at http://www.cdc.gov/niosh/topics/ctrlbanding/.

Table D1. Prescribed uses and manufacturers' OELs (full-shift time-weighted average) for the APIs measured in air

\begin{tabular}{|c|c|c|}
\hline API & Prescribed for* & $\begin{array}{c}\text { Manufacturer's OEL or } \\
\text { hazard control band } \\
\left(\mu \mathrm{g} / \mathrm{m}^{3}\right) \dagger\end{array}$ \\
\hline Buspirone & Anxiety & 10 \\
\hline Captopril & High blood pressure and congestive heart failure & 100 \\
\hline Furosemide & High blood pressure and fluid retention & None published \\
\hline Gabapentin & $\begin{array}{l}\text { Seizures, restless legs syndrome, and } \\
\text { pain from shingles }\end{array}$ & 1,200 \\
\hline $\mathrm{HCTZ}$ & High blood pressure and fluid retention & 100 \\
\hline Hydrocodone & Pain relief or cough suppression & 5 \\
\hline Lisinopril & High blood pressure and heart failure & $1-10$ \\
\hline Levothyroxine & Hypothyroidism & $<1$ \\
\hline Methocarbamol & Muscle pain & None published \\
\hline Methotrexate & $\begin{array}{c}\text { Cancer of the blood, bone, lung, breast, head or neck, } \\
\text { rheumatoid arthritis, or psoriasis }\end{array}$ & 0.3 \\
\hline Naproxen & Pain and fever & 1,000 \\
\hline Triamterene & High blood pressure and fluid retention & 1,000 \\
\hline
\end{tabular}

${ }^{*}[$ PubMed Health 2013]

†Buspirone [U.S. Pharmacopeia 2006], Captopril [U.S. Pharmacopeia 2013a], Gabapentin [Pfizer 2010], HCTZ [Bristol-Myers Squibb Company 2012a], Hydrocodone [Abbott Labs 2011], Lisinopril [Bristol-Myers Squibb Company 2012b], Levothyroxine [Pfizer 2011], Methotrexate [U.S. Pharmacopeia 2013b], Naproxen [Roche 2006], Triamterene [GlaxoSmithKline 2008]. 


\section{References}

Abbott Labs [2011]. Safety data sheet: Vicodin ES tablets. [http://www.abbott.com/global/ url/content/en_US/20.40:40/general_content/General_Content 00183.htm]. Date accessed:

December 2013.

ACGIH [2010]. Industrial ventilation: a manual of recommended practice for design, 27th edition. Cincinnati, OH: American Conference of Governmental Industrial Hygienists (ACGIH).

ACGIH [2013]. 2013 TLVs ${ }^{\circledR}$ and BEIs ${ }^{\circledR}$ : threshold limit values for chemical substances and physical agents and biological exposure indices. Cincinnati, OH: American Conference of Governmental Industrial Hygienists.

AIHA [2013]. AIHA 2013 Emergency response planning guidelines (ERPG) \& workplace environmental exposure levels (WEEL) handbook. Fairfax, VA: American Industrial Hygiene Association.

ASHRAE [2010]. ANSI/ASHRAE Standard 62.1-2010: Ventilation for acceptable indoor air quality. Atlanta, GA: American Society of Heating, Refrigerating, and Air-Conditioning Engineers, Inc.

Bernstein JA, Bernstein DI, Stauder T, Zana L, Bernstein LI [1999]. A cross-sectional survey of sensitization of Aspergillus oryzae-derived lactase in pharmaceutical workers. J Allergy Clin Immunol 103(6):1153-1157.

Brent RL, Tanski S, Weitzman M [2004]. A pediatric perspective on the unique vulnerability and resilience of the embryo and the child to environmental toxicants: the importance of rigorous research concerning age and agent. Pediatrics 113(4 Suppl):935-944.

Bristol-Myers Squibb Company [2012a]. Safety data sheet: Hydrochlorothiazide. [http:// www.bmsmsds.com/msdsweb/]. Date accessed: December 2013.

Bristol-Myers Squibb Company [2012b]. Safety data sheet: Lisinopril. [http://www. bmsmsds.com/msdsweb/]. Date accessed: December 2013.

CFR. Code of Federal Regulations. Washington, DC: U.S. Government Printing Office, Office of the Federal Register.

Connor TH, Sessink PJ, Harrison BR, Pretty JR, Peters BG, Alfaro RM, Bilos A, Beckmann G, Bing MR, Anderson LM, Dechristoforo R [2005]. Surface contamination of chemotherapy drug vials and evaluation of new vial-cleaning techniques: results of three studies. Am J Health Syst Pharm 62(5):475-484.

Cooper C, Dewe P [2008]. Well-being - absenteeism, presenteeism, costs, and challenges. Occup Med (Lond.) 58(8):522-524. 
De Dreu CKW, van Dierendonck D, De Best-Waldhober M [2003]. Conflict at work and individual well-being. In: Schabracq MJ, Winnubst JAM, Cooper CL, eds. Handbook of work and health psychology. 2nd ed. West Sussex, England: John Wiley and Sons, pp. 495-515.

Forsberg K, Mansdorf SZ [2007]. Quick selection guide to chemical protective clothing. 5th ed. Hoboken, New Jersey: Wiley-Interscience.

GlaxoSmithKline [2008]. Safety data sheet: Dyazide capsules. [http://www.msds-gsk. com/0029250e.pdf]. Date accessed: December 2013.

Heron RJL, Pickering FC [2003]. Health effects of exposure to active pharmaceutical ingredients (APIs). Occup Med (Lond.) 53(6):357-362.

Johns G [2010]. Presenteeism in the workplace: a review and research agenda. J Organiz Behav 31(4):519-542.

Ladenson P, Kim M [2008]. Thyroid. In: Goldman L, Ausiello D, eds. Cecil textbook of medicine. 23rd rev. ed. Philadelphia, PA: Saunders Elsevier, pp. 1698-1712.

Lloyd ME, Carr M, McElhatton P, Hall GM, Hughes RA [1999]. The effects of methotrexate on pregnancy, fertility and lactation. QJM 92(10)(Review):551-563.

Neal A, Griffin MA, Hart PM [2000]. The impact of organizational climate on safety climate and individual behavior. Safety Sci 34(1-3):99-109.

Naumann BD, Sargent EV, Starkman BS, Fraser WJ, Becker GT, Kirk GD [1996]. Performance-based exposure control limits for pharmaceutical active ingredients. Am Ind Hyg Assoc J 57(1):33-42.

Naumann BD [2005]. In: Control banding in the pharmaceutical industry. [http://www.aioh. org.au/downloads/documents/ControlBandingBNaumann.pdf]. Date accessed: December 2013.

NIOSH [1997a]. Musculoskeletal disorders and workplace factors: a critical review of epidemiologic evidence for work-related musculoskeletal disorders of the neck, upper extremity, and low back. Cincinnati, OH: U.S. Department of Health and Human Services, Centers for Disease Control and Prevention, National Institute for Occupational Safety and Health, DHHS (NIOSH) Publication No. 97-141. [http://www.cdc.gov/niosh/docs/97-141/]. Date accessed: December 2013.

NIOSH [1997b]. Elements of ergonomics programs: a primer based on workplace evaluations of musculoskeletal disorders. Cincinnati, OH: U.S. Department of Health and Human Services, Centers for Disease Control and Prevention, National Institute for Occupational Safety and Health, DHHS (NIOSH) Publication No. 97-117. 
NIOSH [2004]. NIOSH alert: preventing occupational exposure to antineoplastic and other hazardous drugs in health care settings. Cincinnati, OH: U.S. Department of Health and Human Services, Centers for Disease Control and Prevention, National Institute for Occupational Safety and Health, DHHS (NIOSH) Publication No. 2004-165.

NIOSH [2010]. NIOSH pocket guide to chemical hazards. Cincinnati, OH: U.S. Department of Health and Human Services, Centers for Disease Control and Prevention, National Institute for Occupational Safety and Health, DHHS (NIOSH) Publication No. 2010-168c. [http://www.cdc.gov/niosh/npg/]. Date accessed: December 2013.

NIOSH [2012]. NIOSH list of antineoplastic and other hazardous drugs in health care settings 2012. Cincinnati, OH: U.S. Department of Health and Human Services, Centers for Disease Control and Prevention, National Institute for Occupational Safety and Health, DHHS (NIOSH) Publication No. 2012-150.

NIOSH [2013a]. Health hazard evaluation report: exposures to pharmaceutical dust at an outpatient pharmacy. By Fent KW, Durgam S, Methner M. Cincinnati, OH: U.S. Department of Health and Human Services, Centers for Disease Control and Prevention, National Institute for Occupational Safety and Health, NIOSH Report No. 2010-0078-3177.

NIOSH [2013b]. NIOSH manual of analytical methods. 4th ed. Schlecht PC, O'Connor PF, eds. Cincinnati, OH: U.S. Department of Health and Human Services, Centers for Disease Control and Prevention, National Institute for Occupational Safety and Health, DHHS (NIOSH) Publication No. 94-113 (August 1994); 1st Supplement Publication 96-135, 2nd Supplement Publication 98-119, 3rd Supplement Publication 2003-154. [http://www.cdc.gov/ niosh/docs/2003-154/].

Pfizer [2010]. Safety data sheet: Gabapentin tablets. [http://www.pfizer.com/files/products/ material_safety_data/PZ01158.pdf]. Date accessed: December 2013.

Pfizer [2011]. Safety data sheet: Levothyroxine sodium tablets. [http://www.pfizer.com/files/ products/material_safety_data/PZ01680.pdf]. Date accessed: December 2013.

Pfizer [2012]. Safety data sheet: Methotrexate tablets. [http://www.pfizer.com/files/products/ material_safety_data/PZ00130.pdf]. Date accessed: December 2013.

PubMed Health [2013]. Drugs and supplements. [http://www.ncbi.nlm.nih.gov/ pubmedhealth/s/drugs and supplements/a/]. Date accessed: December 2013.

Roche [2006]. Safety data sheet: Naproxen sodium. [http:/www.roche.com/pages/csds/ english/out/0490628.20110225.8049.pdf]. Date accessed: December 2013.

Schierl R, Herwig A, Pfaller A, Groebmair S, Fischer E [2010]. Surface contamination of antineoplastic drug vials: comparison of unprotected and protected vials. Am J Health Syst Pharm 67(6):428-429. 
Schultz AB, Edington DW [2007]. Employee health and presenteeism: a systematic review. J Occup Rehabil 17(3):547-579.

Stewart WF, Ricci JA, Chee E, Hahn SR, Morganstein D [2003]. Cost of lost productive work time among US workers with depression. JAMA 289(23):3135-3144.

Teichman RF, Fallon LF, Brandt-Rauf PW [1988]. Health effects on workers in the pharmaceutical industry: a review. J Soc Occup Med 38(3):55-57.

U.S. Pharmacopeia [2006]. USP reference standards, safety data sheet: Buspirone hydrochloride. [http://www.usp.org/pdf/EN/referenceStandards/msds/1078802.pdf]. Date accessed: December 2013.

U.S. Pharmacopeia [2013a]. USP reference standards, safety data sheet: Captopril. [http:// www.usp.org/pdf/EN/referenceStandards/msds/1091200.pdf]. Date accessed: December 2013.

U.S. Pharmacopeia [2013b]. USP reference standards, safety data sheet: Methotrexate. [http://www.usp.org/pdf/EN/referenceStandards/msds/1414003.pdf]. Date accessed:

December 2013.

Widera E, Chang A, Chen HL [2010]. Presenteeism: a public health hazard. J Gen Intern Med 25(11):1244-1247.

Zalk DM, Nelson DI [2008]. History and evolution of control banding: a review. J Occup Environ Hyg 5(5):330-346.

Zuskin E, Mustajbegovic J, Schachter EN, Kern J, Deckovic-Vukres V, Pucarin-Cvetkovic J, Nola-Premec IA [2004]. Respiratory findings in pharmaceutical workers. Am J Ind Med 46(5):472-479. 
Keywords: North American Industry Classification System 446110 (Pharmacies and Drug Stores), pharmaceutical dust, pill dust, lisinopril, methotrexate, hazardous drugs, automatic dispensing machines, mail order pharmacy, dust exposures, local exhaust ventilation, eye irritation, respiratory irritation, skin irritation, safety climate, job stress 
The Health Hazard Evaluation Program investigates possible health hazards in the workplace under the authority of the Occupational Safety and Health Act of 1970 (29 U.S.C. § 669(a)(6)). The Health Hazard Evaluation Program also provides, upon request, technical assistance to federal, state, and local agencies to investigate occupational health hazards and to prevent occupational disease or injury. Regulations guiding the Program can be found in Title 42, Code of Federal Regulations, Part 85; Requests for Health Hazard Evaluations (42 CFR Part 85).

\section{Disclaimer}

The recommendations in this report are made on the basis of the findings at the workplace evaluated and may not be applicable to other workplaces.

Mention of any company or product in this report does not constitute endorsement by the National Institute for Occupational Safety and Health (NIOSH).

Citations to Web sites external to NIOSH do not constitute NIOSH endorsement of the sponsoring organizations or their programs or products. NIOSH is not responsible for the content of these Web sites. All Web addresses referenced in this document were accessible as of the publication date.

\section{Acknowledgments}

Analytical Support: Bureau Veritas North America

Desktop Publishers: Mary Winfree

Editor: Ellen Galloway

Industrial Hygiene Field Assistance: Catherine Beaucham and Karl Feldmann

Logistics: Donnie Booher and Karl Feldmann

Medical Field Assistance: Kenneth Bennett

\section{Availability of Report}

Copies of this report have been sent to the employer, employees, and union at the facility. The state and local health department and the Occupational Safety and Health Administration Regional Office have also received a copy. This report is not copyrighted and may be freely reproduced.

This report is available at http://www.cdc.gov/niosh/hhe/reports/pdfs/2012-0044-3199.pdf.

Recommended citation for this report:

NIOSH [2013]. Health hazard evaluation report: evaluation of safety climate, health concerns, and pharmaceutical dust exposures at a mail order pharmacy. By Fent KW, Tapp L, Wiegand

D. Cincinnati, OH: U.S. Department of Health and Human Services, Centers for Disease Control and Prevention, National Institute for Occupational Safety and Health, NIOSH Report No. 2012-0044-3199. 
Delivering on the Nation's promise:

Safety and health at work for all people through research and prevention

To receive NIOSH documents or more information about occupational safety and health topics, please contact NIOSH:

Telephone: 1-800-CDC-INFO (1-800-232-4636)

TTY: 1-888-232-6348

CDC INFO: www.cdc.gov/info

or visit the NIOSH Web site at www.cdc.gov/niosh

For a monthly update on news at $\mathrm{NIOSH}$, subscribe to NIOSH eNews by visiting www.cdc.gov/niosh/eNews. 